\title{
VARIAÇÃO DE CARACTERES E SUAS IMPLICAÇÕES PARA O MELHORAMENTO GENÉTICO DA MADEIRA SERRADA EM Eucalyptus urophylla
}

\author{
LOTHAR SCHACHT \\ Engenheiro Florestal
}

Orientador: Prof: Dr. JOSÉ NIVALDO GARCIA

Dissertação apresentada à Escola Superior de Agricultura "Luiz de Queiroz", para obtenção do título de Mestre em Ciências - Área de Concentração: Ciências Florestais

PIRACICABA

Estado de São Paulo - Brasil

Janeiro - 1998 
Dados Internacionais de Catalogação na Publicação (CIP) DIVISĀO DE BIBLIOTECA E DOCUMENTAÇĀO - Campus "Luiz de Queiroz"/USP Schacht, Lothar
Variação de caracteres e suas implicações para o melhoramento genético da
madeira serrada em Eucalyptus urophy/la / Lothar Schacht. - Piracicaba, 1998. 58 p. : il.

Dissertação (mestrado) - Escola Superior de Agricultura Luiz de Queiroz, 1998. Bibliografia.

1. Crescimento vegetal 2. Madeira serrada de eucalipto 3. Melhoramento genético vegetal 4 . Rachadura 5. Secagem 1 . Titulo 


\section{VARIAÇÃO DE CARACTERES E SUAS IMPLICAÇÕES PARA O MELHORAMENTO GENÉTICO DA MADEIRA SERRADA EM Eucalyptus urophylla}

\section{LOTHAR SCHACHT}

Aprovada em: 02.04.1998

Comissão Julgadora:

Prof. Dr. José Nivaldo Garcia ESALQ/USP

Prof. Dr. Roland Vencovsky ESALQ/USP

Prof. Dr. Carlito Calil Júnior EESC/USP

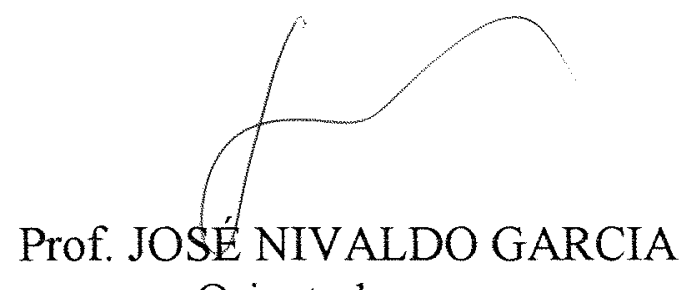

Orientador 
À futura flora e fauna de sub-bosque das florestas de eucalipto manejadas para serraria. 


\section{AGRADECIMENTOS}

- Ao Prof. Dr. José Nivaldo Garcia, pela amizade, orientação e estímulo no trabalho de tese.

- Aos Professores do Departamento de Genética: Dr. Isaías O. Geraldi, Dr. Branco de M. Filho e em especial ao Dr. Roland Vencovsky pela orientação e auxílio nas análises genético quantitativas.

- Aos professores e colegas do Departamento de Matemática e Estatística, Dr. Décio Barbin, Dr. Antônio F. Iemma, em especial ao Dr. Tadeu dos Santos Dias e ao doutorando Luiz Maria Salvarrey pelo auxílio nos problemas estatísticos e análises no SAS.

- Aos Professores do Departamento de Ciências Florestais Dr. Antônio Natal Gonçalves, Dr. Luiz Carlos Estradiviz Rodrigues, Dr. Hilton Tadeu Z. Couto, Dr. João Batista e Dr. Ivaldo P. Jankovsky pelo apoio recebido.

- Ao Prof. Dr. Mário Ferreira pelo incentivo e apoio recebido no estudo deste material.

- Ao Prof. Dr. José O. Brito pelo apoio recebido na fase de coleta de dados.

- Ao CNPq pela bolsa de estudos oferecida durante o desenvolvimento do trabalho, o qual possibilitou envolvimento integral.

- Ao Marcelo Correa Alves do CIAGRI, pelo auxilio nas questões relativas ao uso do SAS.

- Ao Dr. François F. Malan, da África do Sul, pelas inúmeras sugestões pertinentes à coleta dos dados.

- Ao Dr. Jason Hsu, da Universidade de Ohio (USA), pelo auxilio prestado no método de comparação múltipla com o melhor. 
- A Champion Papel e Celulose Ltda, nas pessoas dos engenheiros João Comério e Aloísio Xavier e técnicos de campo Jair, Márcio, Nilson, Fernandes e Valdecir pelo apoio e auxílio recebido na coleta de dados em campo.

- Ao técnico Luis Eduardo Facco pelo auxílio na serraria, correções e editoração.

- A todos os funcionários da Serraria da ESALQ, em especial ao Wilson Zani Filho.

- Ao IPT de São Paulo pelo processamento dos blocos das toras.

- A Indusparquet S.A. pela doação dos sarrafos separadores.

- Ao Vítor G. Barchet e Isaac S. Benchimol, pelo auxílio na coleta de dados na serraria.

- À Angelina, Carla, Cláudio, Girlei, Gisèle, Leila, Marli, Milton, Natália, Samir, Sebastião, Tarcísio, e todos demais colegas de pós-graduação e graduação que auxiliaram neste trabalho.

- A todos funcionários da ESALQ que auxiliaram direta ou indiretamente na realização deste trabalho, em especial aos das bibliotecas do IPEF, Central e da Genética.

- Aos meus pais e familiares pela compreensão nos momentos dificeis. 


\section{SUMÁRIO}

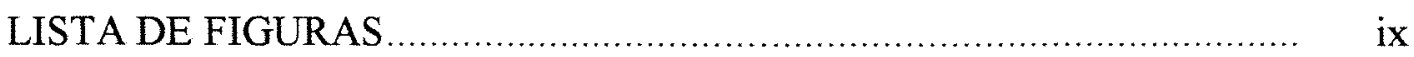

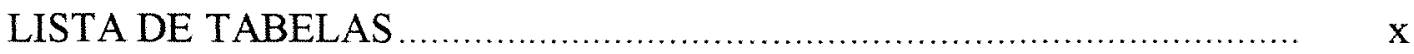

LISTA DE ABREVIATURA E SÍMBOLOS ….................................. xi

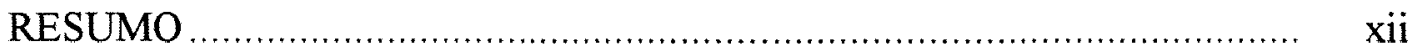

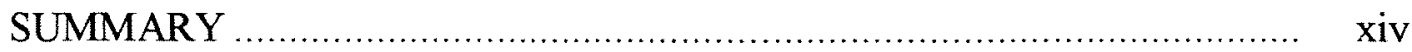

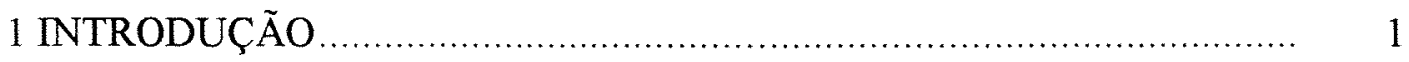

2 REVISÃO DE LITERATURA ……............................................ 3

2.10 Eucalyptus urophylla .................................................................

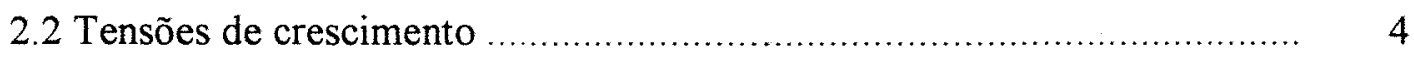

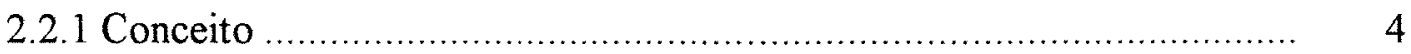

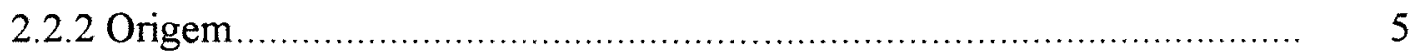

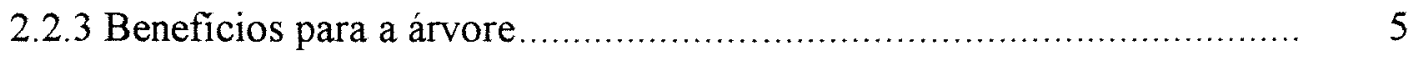

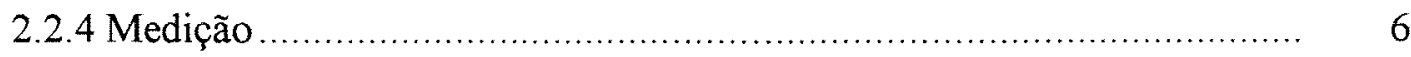

2.2.5 Defeitos de utilização comercial da madeira devidos às tensões de cres-

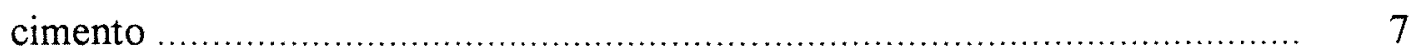

2.2.5.1 Rachaduras de extremidades de toras ........................................ 7

2.2.5.2 Rachaduras da madeira serrada ................................................ 9

2.2.5.3 Empenamentos da madeira serrada ….......................................

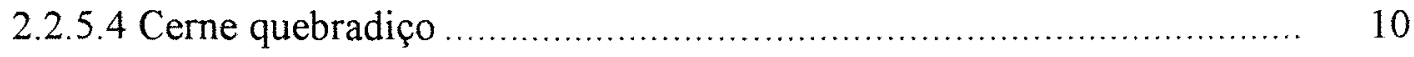

2.2.6 Métodos para reduzir seus defeitos ............................................... 11

2.2.7 Variações intra-árvores ............................................................... 12 


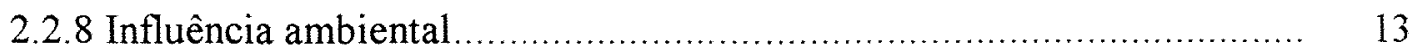

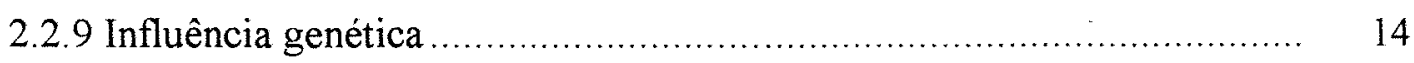

2.2.10 Variação intra-clonal .............................................................. 15

3 VARIAÇÃO DE RACHADURAS DE TOPO EM TORAS DE

Eucalyptus urophylla: UMA INVESTIGAÇÃO METODOLÓGICA........... 17

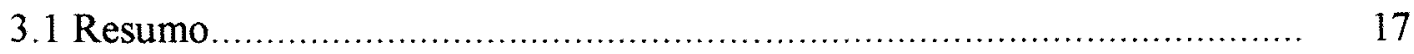

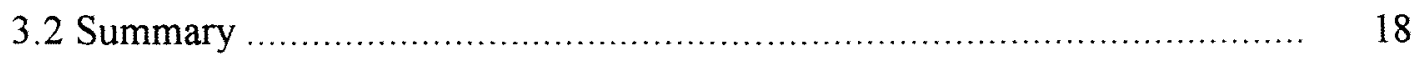

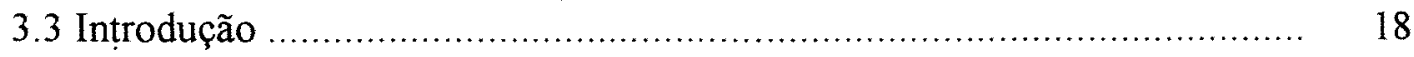

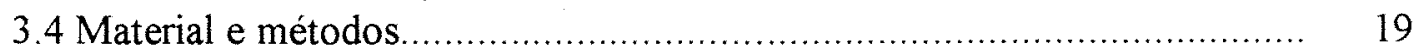

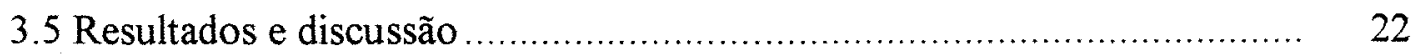

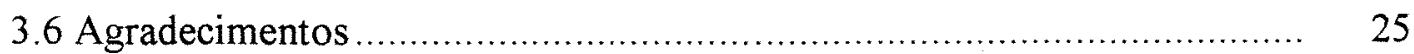

4. VARIAÇÃO GENÉTICA DE INDICADORES DE TENSÕES DE CRESCIMENTO EM CLONES DE Eucalyptus urophylla ....................... 26

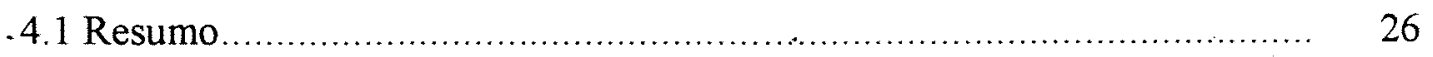

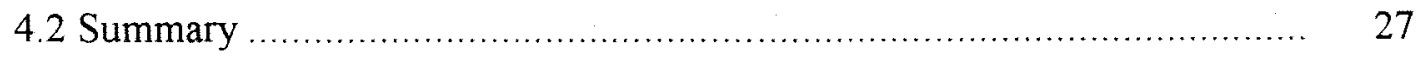

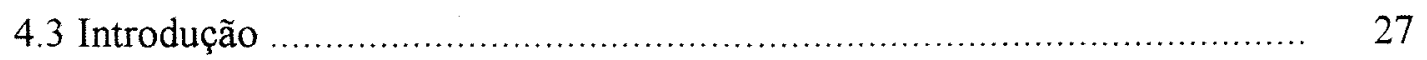

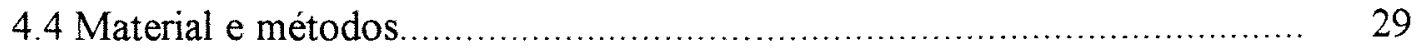

4.5 Resultados e discussão …......................................................... 35

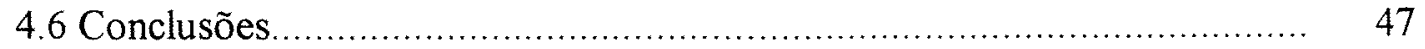

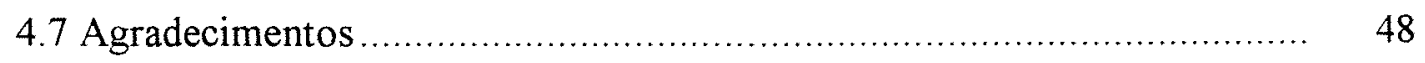

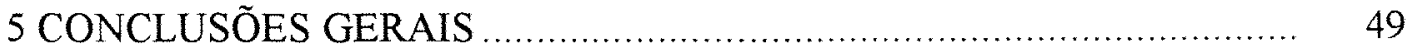

REFERÊNCIAS BIBLIOGRÁFICAS _........................................... 51 


\section{LISTA DE FIGURAS}

1 Distribuição teórica das deformações de crescimento (longitudinais,

Página tangenciais e radiais) em duas árvores de diâmetros diferentes. As áreas de tração estão marcadas com sinal + e as de compressão com sinal -

2 Variação da grã espiralada dos anéis de crescimento da medula para casca em (a) ramets propagados de ortetes maduros e (b) rametes propagados de ortetes juvenis (Nicholls et al. 1977)

3 Desenvolvimento das rachaduras de topo das toras após o secionamento ...

4 Diferenças das médias de SEP para cada tratamento e posição de altura no fuste da árvore

5 Processo de obtenção da costaneira (a), da viga central da mesma (b) e da medição do comprimento das rachaduras da tábua (c)

6 Comparação de médias dos caracteres HT - altura total da árvore (a); RP rachaduras de topo de toras com saco plástico e V - flecha do vigote (b); TB - rachaduras de tábuas e E - encurvamento de tábuas (c); onde B são os maiores valores e $\mathrm{W}$ são os menores valores a um nível de $5 \%$ de probabilidade. 


\section{LISTA DE TABELAS}

Página

1 Análise de variância de SEP no $4^{\circ}$ e $6^{\circ}$ dia de medição..

2 Esquema da análise de variância entre e dentro das árvores

3 Média geral, intervalos de variação da média dos clones, valores de $\mathrm{F}$ para a diferença entre clones e estimativas da herdabilidade para todas as variáveis estudadas.

4 Componentes da variância estimados pelo método REML

5 Análise de variância para os caracteres RP e V, considerando a variação entre e dentro de árvores

6 Médias de flecha do vigote da costaneira (V) por clone em dois níveis de altura. Os respectivos coeficientes de variação encontram-se entre parênteses.

7 Médias das rachaduras de topo de toras com saco plástico (RP) por clone em dois níveis de altura. Os respectivos coeficientes de variação encontram-se entre parênteses 
8 Correlações genéticas (triângulo superior) e correlações fenotípicas (triângulo inferior) com o respectivo nível de significância. 


\section{LISTA DE ABREVIATURAS E SÍMBOLOS}

$\mathrm{BL}$ - soma dos comprimentos máximos de rachaduras de cada bloco, em $\mathrm{cm}$;

$\mathrm{CN}$ - conicidade da árvore, razão da circunferência a 0,005 .HT pela circunferência a 1/3 de HT;

$\mathrm{CP}$ - comprimento da copa da árvore, em m;

D - déficit de pressão do vapor de água, em centímetros de $\mathrm{Hg}$ (mercúrio);

DAP - diâmetro à altura do peito (1,3 $\mathrm{m}$ de altura do solo), $\mathrm{em} \mathrm{cm}$;

DS - DAP sem casca, em cm;

E - encurvamento médio, ou flecha média das tábuas por bloco, $\mathrm{em} \mathrm{cm}$;

F - flecha da costaneira, em cm;

HF - altura do fuste da árvore, em m;

HT - altura total da árvore, em m;

REML - método da máxima verossimilhança restrita;

$\mathrm{RP}$ - rachaduras de extremidade de tora coberta com saco plástico, em \%;

RT - rachaduras de extremidade de tora com o topo livre, em \%;

SEP - "splitting estimated percentage" - porcentagem estimada de rachaduras, em \%;

ST - fator de estabilidade, ou quociente DS / HT;

TB - média dos comprimentos de rachaduras nas duas extremidades das tábuas por bloco, em cm;

$\mathrm{V}$ - flecha do vigote ou da peça central da costaneira, $\mathrm{em} \mathrm{cm}$. 


\title{
VARIAÇÃO DE CARACTERES E SUAS IMPLICAÇÕES PARA O MELHORAMENTO GENÉTICO DA MADEIRA SERRADA
}

\author{
EM Eucalyptus urophylla
}

\author{
Autor: LOTHAR SCHACHT \\ Orientador: Prof. Dr. JOSÉ NIVALDO GARCIA
}

\section{RESUMO}

O objetivo principal do presente trabalho foi avaliar o potencial de melhoramento genético para importantes caracteres de qualidade da madeira que estão associados às tensões de crescimento. Para tanto, realizaram-se dois estudos em um banco clonal de 9 anos de idade de Eucalyptus urophylla S.T.Blake. No primeiro, aplicou-se em 20 árvores um rápido e melhorado método de avaliação das rachaduras de extremidade de toras para quantificarem-se as influências do clone, posição no fuste, tempo e condições de secagem. Encontrou-se uma alta correlação na intensidade das rachaduras entre faces adjacentes, fato este que possibilitou o estudo das condições de secagem das extremidades das toras. Verificou-se uma altíssima intensidade de rachadura nas extremidades expostas à secagem livre quando comparada com aquela observada nas extremidades protegidas, o que permite concluir que grande parte das rachaduras de extremidade de toras é devida à interação das tensões de crescimento com as de secagem. Verificou-se ainda uma significativa diminuição da intensidade das mesmas com o aumento da altura ao longo do fuste da árvore. No segundo estudo, 148 árvores de 27 clones foram derrubadas e serradas para o estudo da variação genética de indicadores de tensão de crescimento. Caracteres relativos à tensão de crescimento como rachaduras de toras, de tábuas, empenamentos da madeira serrada e caracteres silviculturais como diâmetro à altura do peito sem casca (DAP), altura total da árvore (HT), altura do fuste, comprimento de copa e conicidade do fuste foram considerados para estimarem-se as herdabilidades no sentido amplo e as correlações genéticas e 
fenotípicas entre os caracteres. Os resultados mostraram que as rachaduras e os empenamentos de toras e/ou madeira serrada são altamente herdáveis e que não existe correlação genética entre o DAP e qualquer um destes caracteres de qualidade da madeira. A porcentagem de rachaduras de topo de toras, a flecha da primeira costaneira ou a flecha do vigote desta, obtidas em condições padronizadas, são caracteres adequados para seleção que podem melhorar simultaneamente as rachaduras e os empenamentos da madeira serrada verde. A significativa correlação negativa das rachaduras e empenamentos com o quociente DAP/HT, chamado fator de estabilidade, possibilita também o melhoramento destes caracteres através de seleção indireta, apresentando a vantagem de ser um indicador não destrutivo. 


\title{
VARIATION OF TRAITS AND THEIR IMPLICATIONS IN THE GENETIC IMPROVEMENT OF Eucalyptus urophylla SAW LUMBER
}

\author{
Author: LOTHAR SCHACHT \\ Adviser: Prof. Dr. JOSÉ NIVALDO GARCIA
}

\section{SUMMARY}

The main objective of this work was to evaluate the potential genetic improvement of important wood quality traits associated with growth stresses. Two studies were made in a 9 years old clonal bank of Eucalyptus urophylla S.T.Blake. In the first study, a quick and improved method to evaluate the end splitting of logs was applied to 20 trees in order to quantify the influence of clone, position in the stem, time and drying conditions. A high correlation in the intensity of splits between adjacent faces was found, which allowed the study of the drying conditions on the log ends. A very high splitting intensity was verified when the log end was exposed to free drying, in comparison with the protected log end. This allows infering that a great part of the log end splits arise from the interaction of growth and drying stresses. A significant reduction of the log end splits along the stem from the bottom to the top was also verified. The second study involved 148 trees of 27 clones which were felled and sawed for studying the genetic variation of growth stress indicators. Traits concerning growth stress as $\log$ end splitting, end boards splitting and lumber warping were taken in several positions along the tree stem and some silvicultural traits as diameter at breast height within bark (DBH), total height of the tree (THT), crown length and stem tapering were taken for estimating broad sense heritabilities and genetic and phenotypic correlations. The results showed that splits and warping of logs and/or sawn lumber are highly heritable and that there is no genetic correlation between DBH and any of these wood quality traits. The log end splitting percentage, the deflection of the first slab or the deflection of the beam cut from it, obtained by standard conditions, are considered 
very good characters for selection which can improve simultaneously the splits and warping of the saw lumber. The significant negative correlation of the DBH/THT ratio, called stability factor, with the splits and warping, also allows the improvement of these traits by indirect selection, with the advantage of being a non destructive indicator. 


\section{INTRODUÇÃo}

A difusão do uso de madeira maciça no mundo, com qualidade e durável, tem uma fundamental importância para diminuição da concentração de $\mathrm{CO}_{2}$ na atmosfera e do conseqüente efeito estufa.

Das madeiras de reflorestamento, o uso do Pinus tem sido amplamente difundido em substituição às espécies nativas, porém a sua madeira no Brasil não é a mais adequada para usos externos ou que exigem maior resistência mecânica. Surge como alternativa o eucalipto, porém a utilização deste gênero tem sido desprezível no Brasil, devido a um certo tabu e ainda disponibilidade de espécies nativas.

$\mathrm{Na}$ Nova Zelândia árvores de eucalipto com mais de 50 anos estão sendo utilizadas para serraria, mas com rendimento imprevisível, sendo que a tendência atual é pesquisar material mais jovem (Cown $\left.{ }^{1}, 1995\right)$. O principal problema é que as toras podem conter uma série de defeitos não detectados facilmente pela sua aparência externa, o que diminui o rendimento da madeira serrada.

A ampla variação na qualidade da madeira entre e dentro das espécies de eucalipto, causada por variações do genótipo e do ambiente tem levado aos relativos insucessos da utilização do eucalipto como madeira serrada no Brasil. A literatura também é rica em comentários sobre o potencial de melhoramento da madeira serrada de eucalipto, porém praticamente não existem pesquisas e resultados efetivos no Brasil. Os poucos estudos são geralmente com Eucalyptus grandis, na África do Sul.

\footnotetext{
${ }^{1}$ COWN, D. Comunicação pessoal, 1995.
} 
Uma extensiva revisão bibliográfica possibilitou inicialmente conhecer as causas mais importantes das variações de caracteres associados às tensões de crescimento. Estabeleceu-se então, uma metodologia de estudo destas variações, contornando-se as limitações do banco clonal como um experimento e por não ser este conduzido e manejado exatamente para serraria.

As rachaduras e deformações da madeira serrada verde são causadas essencialmente pelas tensões de crescimento. O conhecimento das variações genéticas existentes nestas características são de fundamental importância para a difusão do uso da madeira serrada do eucalipto, razão pela qual procedeu o presente estudo sobre o Eucalyptus urophylla S.T.Blake, uma das espécies com grande variação fenotípica nas suas características morfológicas. 


\section{REVISÃO DE LITERATURA}

\subsection{O Eucalyptus urophylla}

O E. urophylla é uma das duas espécies que não ocorrem na Austrália. A distribuição geográfica natural da espécie é o arquipélago de Sumba, leste da Indonésia, em altitudes que variam de 100 a 2960 m (Vercoe \& House, 1992).

$\mathrm{Na}$ área de distribuição geográfica natural, a espécie cresce em um clima tropical quente e úmido, com uma estação seca variando de 2 a 8 meses. As árvores geralmente alcançam de 22 a $45 \mathrm{~m}$ de altura e mais de um metro de diâmetro (Eldridge, 1994).

Navarro de Andrade introduziu no Brasil o E. urophylla num arboreto em Rio Claro em 1919, sob o nome Eucalyptus alba, provavelmente usando sementes de árvores do Horto Botânico de Bogor (Eldridge, 1994). O E. urophylla tornou-se conhecido somente após a sua formal descrição (Blake², 1977 citado por Pryor et al., 1995).

A ampla variabilidade de caracteres morfológicos, principalmente tamanho do fruto e tipo de casca, tem resultado em uma confusão histórica na sua identificação botânica (Martin \& Cossalter, 1975). Além disso, a contínua variação no tamanho do fruto e outras características morfológicas tem inibido a separação taxonômica da espécie em distintas formas (Eldridge, 1994).

\footnotetext{
${ }^{2}$ BLAKE, S.T. Four new species of Eucalyptus. Austrobaileya, v.1, n.1, p.7-9, 1977.
} 
Recentemente reclassificou-se a espécie E. urophylla, separando-se duas novas espécies, Eucalyptus orophila e Eucalyptus wetarensis. A espécie E. urophylla distingue-se das espécies citadas anteriormente pelas folhas largas e lanceoladas com uma cauda longa e típica e pelos frutos na maioria das vezes menores que $10 \mathrm{~mm}$ de diâmetro (Pryor et al., 1995).

A pressão sobre os povoamentos originais na sua região de origem tem levado a quase extinção do E. urophylla em algumas ilhas, tais como a de Solor (Pryor et al., 1995).

O híbrido resultante do cruzamento do E. urophylla foi o que apresentou menor intensidade de rachaduras de extremidade num ensaio de 3 híbridos de Eucalyptus grandis. O mesmo também não apresentou influência do ambiente quando analisado em 6 sítios diferentes (Malan, 1993), o que pode ser explicado pelo alto controle genético das rachaduras de topo e pela plasticidade do híbrido.

\subsection{Tensões de crescimento}

\subsubsection{Conceito}

Tensões de crescimento são forças encontradas em fustes de árvores verdes, as quais podem ser orientadas longitudinalmente, tangencialmente e radialmente (Kubler, 1987). Estas forças não devem ser confundidas com as tensões resultantes do peso da copa da árvore, ou da tensão da seiva, ou mesmo as resultantes da madeira de reação e das tensões de secagem.

A madeira de reação, que ocorre num único lado do fuste e galhos, é madeira de tração em folhosas e madeira de compressão em coníferas. A madeira de reação torna as tensões longitudinais diversas vezes maiores que as tensões de crescimento da madeira normal (Jacobs, 1945). 


\subsubsection{Origem}

As tensões de crescimento originam-se do câmbio, tecido responsável pelo crescimento diametral das árvores, formando uma camada periférica que permanece com o mesmo nível de tensão ao longo da vida da árvore (Jacobs, 1965). O mecanismo de geração destas tensões de crescimento consiste no encurtamento longitudinal e expansão lateral das células (Boyd, 1972). Este encurtamento gera uma tensão de tração longitudinal próximo ao câmbio da árvore, a qual decresce gradativamente mudando de tração longitudinal para compressão longitudinal em direção à medula por imposição da necessidade de autoequilíbrio. A expansão lateral das células provoca uma compressão no sentido tangencial e uma tração no sentido radial sendo esta última de valor nulo na periferia pois a casca não provoca resistência neste sentido (Kubler, 1987).

\subsubsection{Benefícios para a árvore}

Nicholson (1973) verificando que as variações periféricas dentro das árvores eram maiores que entre árvores concluiu que a tensão de crescimento tem a função de estabilidade em árvores inclinadas ou em copas assimétricas. Jacobs (1938) cita a mesma função de estabilidade para as tensões de crescimento. Posteriormente, Nicholson et al. (1975) afirmaram que as tensões de crescimento possibilitam que a árvore alcance o ótimo posicionamento da sua copa em relação ao ambiente.

A tensão na madeira minimiza danos causados pela compressão quando as árvores são flexionadas pelo vento, pois a madeira é muito mais resistente à tração do que a compressão (Boyd, 1950). A compressão tangencial das tensões de crescimento também é vital para impedir a formação de rachaduras devido à geadas $\left(\mathrm{Kubler}^{3}, 1983\right.$ citado por Kubler, 1987) e à severa tensão da água em períodos de seca (Kubler, 1987), ou mesmo impedir a maior tendência de rachaduras nos raios (Mattheck \& Kubler, 1995).

\footnotetext{
${ }^{3}$ KUBLER, H. Mechanism of frost crack formation in trees - a review and synthesis. Forest Science, v. 29, n. 3, p. $559-568,1983$.
} 


\subsubsection{Medição}

Quando uma tensão é aplicada sobre a madeira, produz-se uma deformação que é medida pela variação dimensional. A deformação é proporcional à tensão (até o limite de elasticidade), sendo que a razão entre a tensão e a deformação é expressa como módulo de elasticidade, a qual é considerada característica da espécie. A tensão, que pode ser de tração ou compressão, é medida como pressão, ou seja, uma força aplicada sobre uma área.

Dada a impossibilidade de medir-se a tensão de crescimento diretamente, ela é determinada como sendo o produto da deformação pelo módulo de elasticidade. Geralmente estas tensões não são quantificadas, medindo-se somente as deformações de crescimento. As deformações associadas às respectivas componentes da tensão de crescimento são muito pequenas, e portanto são geralmente expressas em microdeformação $\left(1 \mu \in=1 \mu \mathrm{m} / \mathrm{m}=10^{-6} \mathrm{~m} / \mathrm{m}\right)$. Alguns estudos, como por exemplo o de Garcia \& Rocha (1996) mostram existir grande variabilidade intra e entre árvores no módulo de elasticidade, mesmo dentro da mesma espécie, razão pela qual Garcia (1992) recomenda trabalhar com a deformação de crescimento.

A precisão dos diversos métodos de medição das tensões de crescimento na periferia da árvore tem sido contestada, devido aos efeitos ocultados ou reduzidos da madeira remanescente onde as amostras são retiradas (Garcia, 1992 e Mattheck \& Kubler, 1995). Um método preferido e recomendável tem sido o método do corte radial usado por Frank Dietrich do Kernforschungszentrum de Karlsruhe, na Alemanha, para medir tensões de crescimento tangenciais (Mattheck \& Kubler, 1995).

As tensões de crescimento mais severas e variáveis são as longitudinais, razão pela qual a maioria dos estudos tem sido a elas concentradas (Wilkins, 1986).

A avaliação visual das tensões de crescimento somente tem sido possível na madeira de reação, onde a tortuosidade do fuste e os galhos podem produzir sintomas de correção direcional (Mattheck \& Kubler, 1995). 


\subsubsection{Defeitos de utilização comercial da madeira devidos às tensões de crescimento}

\subsubsection{Rachaduras de extremidades de toras}

As tensões de crescimento longitudinais são parcialmente liberadas quando a árvore é derrubada e traçada em toras. O traçamento causa principalmente a redistribuição e transformação das tensões longitudinais em tensões transversais e tensões de cisalhamento. Esta liberação é exponencialmente decrescente, até à distância de 1,3 vezes o diâmetro da extremidade $\mathrm{da}$ tora. As variações observadas experimentalmente a este valor podem ter sido causadas por variação das constantes elásticas, especialmente as transversais (Wilhelmy \& Kubler, 1973).

Para uma simplificada compreensão do desenvolvimento das rachaduras deve-se primeiro entender a distribuição teórica das deformações de crescimento da Figura 1 (Kubler ${ }^{4}$, 1959 citado por Kubler, 1987) e que a madeira comporta-se anisotropicamente conforme à direção das fibras. $\mathrm{O}$ comportamento anisotrópico pode ser exemplificado na função estrutural: a madeira é muitas vezes mais resistente à tensão paralela do que normal às fibras, ou na direção das fibras, a resistência à tração é diversas vezes superior que à compressão (Dinwoodie ${ }^{5}, 1975$ citado por Wilkins, 1986), com algumas exceções para esta última comparação nas espécies brasileiras.

Vários trabalhos citados por Kubler (1987) sugerem que o desenvolvimento das rachaduras de topo das toras após o traçamento é exponencial decrescente. Marder (1997) explica fisicamente o desenvolvimento das rachaduras através de três fases e a superficie rugosa das mesmas pela inconstante velocidade de propagação da fratura. As rachaduras de topo devido às tensões de crescimento geralmente atingem a sua máxima intensidade após um período de 72 horas após o traçamento (Malan, 1979).

\footnotetext{
${ }^{4}$ KUBLER, H. Studies on growth stresses in trees. 2. Longitudinal stresses. Holz als Roh- und Werkstof, v. 17, n.2, p.44-54, 1959b. In German.

${ }^{s}$ DINWOODIE. J.M. Timber - a review of the structure-mechanical property relationship. J. Microscopy, v.104, n.1, p.3-32, 1975.
} 

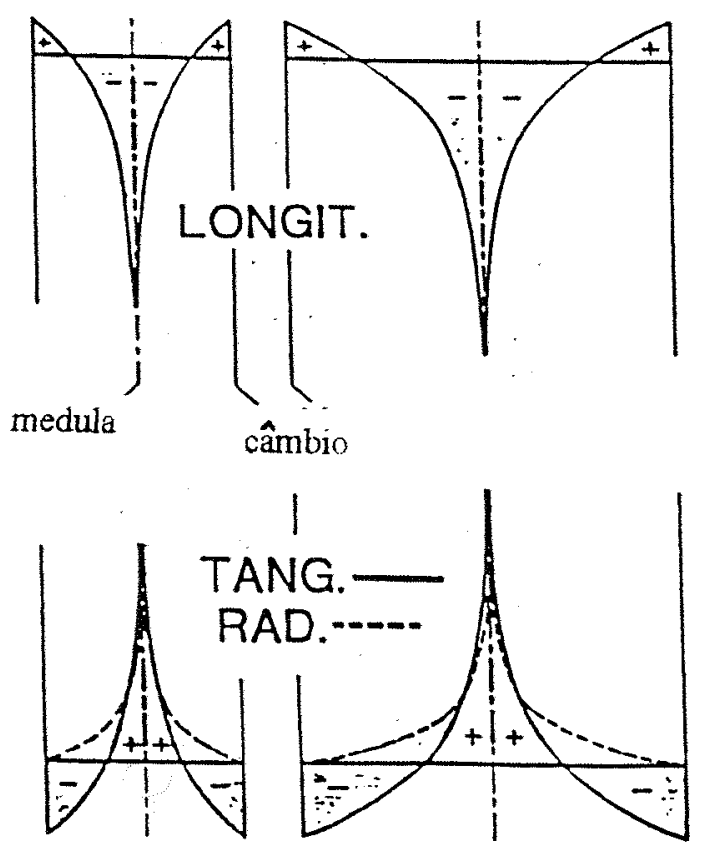

Figura 1: Distribuição teórica das deformações de crescimento (longitudinais, tangenciais e radiais) em duas árvores de diâmetros diferentes. As áreas de tração estão marcadas com sinal $+\mathrm{e}$ as de compressão com sinal -

Quando a grã da madeira é entrecruzada, as rachaduras de topo são reduzidas (Malan $\left.{ }^{6}, 1994\right)$, especialmente na proximidade de nós e galhos, conforme citações de Kubler (1987).

Distinguem-se 5 tipos de rachaduras que degradam a madeira, sendo que duas são resultantes das tensões de crescimento (rachaduras de cerne ou de extremidade e rachaduras laterais), uma do colapso, uma do processo da secagem e outra do próprio efeito da derrubada. As rachaduras são um fenômeno complexo, e como

\footnotetext{
${ }^{6}$ MALAN, F.S. Comunicação pessoal, 1994.
} 
dependem do tempo para a sua manifestação os vários tipos de rachaduras podem interagir entre si (Bariska, 1990).

$\mathrm{Na}$ verdade tanto as rachaduras de colapso como de secagem são ocasionadas pelo processo de secagem. As rachaduras de secagem acima citadas são as ocasionadas pela retratibilidade da madeira, quando o teor de umidade da madeira cai abaixo do ponto de saturação das fibras, isto é, quando não há mais água livre no ponto considerado. Enquanto as rachaduras de colapso são resultantes de uma contração anormal da madeira que ocorre acima do ponto de saturação de fibras.

\subsubsection{Rachaduras da madeira serrada}

O maior gradiente de tensões em toras de menor diâmetro também está associado com a tendência de rachaduras (Hillis, 1978; Wilkins, 1986 e Wilkins \& Kitahara, 1991a, 1991b).

Os efeitos das tensões de crescimento sobre a qualidade de madeira serrada podem ser determinados pela medição do comprimento de tábuas lívre de rachaduras, adotando uma técnica padrão de serragem das toras (Villiers, 1973).

Um dos métodos para prever os defeitos da madeira serrada preconiza a medição da circunferência antes e 72 horas após o traçamento das toras. Um aumento de $0,20 \%$ nesta circunferência, devido às rachaduras, resultou em um rendimento em tábuas de aproximadamente $40 \%$, enquanto que um aumento de $2,42 \%$ resultou em um rendimento de $32,5 \%$ (Villiers, 1973).

\subsubsection{Empenamentos da madeira serrada}

Para um mesmo nível de tensão de crescimento periférica, toras de maior diâmetro produzem proporcionalmente um maior volume de madeira com menos distorção do que as de menor diâmetro (Hillis, 1978). Isto pode ser explicado pela relativa menor taxa de variação da tensão de crescimento na direção radial. 
Uma forma de avaliar as conseqüências das tensões de crescimento sobre o empenamento da madeira serrada é a medição da flecha que a mesma forma no sentido longitudinal da árvore, constituindo um importante indicador de seleção de árvores para serraria (Garcia, 1995).

A equação apresentada por Garcia (1995) $\mathrm{f}=\frac{3 \cdot \mathrm{L}^{2} \cdot \varepsilon_{\mathrm{p}}}{4 \cdot \mathrm{D}}$

onde: $\mathrm{f}=$ flecha

$\mathrm{L}=$ comprimento da peça

$\varepsilon_{\mathrm{p}}=$ deformação de crescimento, medida na periferia da árvore

$\mathrm{D}=$ diâmetro da árvore no ponto considerado

demonstra que para a seleção de árvores para serraria é importante a relação $\varepsilon_{\mathrm{p}} / \mathrm{D}$ e não apenas $\varepsilon_{\mathrm{p}}$. Isto também explica porque as rachaduras de extremidades da tora e os empenamentos na madeira serrada se agravam com o aumento da altura na árvore (Garcia, 1995).

\subsubsection{Cerne quebradiço}

Se as tensões de crescimento periféricas forem suficientemente altas, as forças de compressão internas excedem a resistência da madeira verde à compressão (Boyd, 1950 e Mattheck \& Kubler, 1995) e ativam a sensibilidade dos raios às tensões transversais formando microrachaduras (Mattheck \& Kubler, 1995) denominadas de cerne quebradiço. Este é freqüentemente dificil de detectar visualmente nas toras (Haslet, 1988, 1990 e Page, 1978) mas pode ser detectado pelo aspecto felpudo e de fibras quebradas na superfície de corte transversal à direção da grã, ou por uma coloração mais pálida que a normal na madeira (Skolmen, 1973). 
Quanto maior o diâmetro da árvore, maiores serão as forças de compressão no centro da árvore, ocasionando a formação do cerne quebradiço. Por exemplo, uma árvore de $E$. regnans de $15,2 \mathrm{~cm}$ de diâmetro com uma tensão periférica de $10,3 \mathrm{MPa}\left(105 \mathrm{Kgf} / \mathrm{cm}^{2}\right)$ desenvolve teoricamente uma tensão de compressão de aproximadamente $50 \mathrm{Mpa}\left(506 \mathrm{Kgf} / \mathrm{cm}^{2}\right)$ na região da medula. Considerando que a resistência a compressão paralela às fibras nesta espécie é de $30 \mathrm{MPa}\left(302 \mathrm{Kgf} / \mathrm{cm}^{2}\right)$ (Bolza \& $\mathrm{Kloot}^{7}, 1963$ citado por Chafe, 1979), é compreensível que a acumulação de tensões de compressão com o aumento do diâmetro formará cerne quebradiço (Chafe, 1979).

\subsubsection{Métodos para reduzir estes defeitos}

Vários Métodos tem sido propostos para reduzir os efeitos das tensões de crescimento. Um deles é o anelamento de árvores 5 a 17 meses antes do seu corte, o qual reduz as rachaduras de toras, mas aumenta o ataque de insetos que degradam a madeira (Villiers, 1973). A simples aspersão com água das toras reduz as tensões de crescimento (Haslett, 1988, 1990). Outros experimentos indicam que a fixação de cintas no topo das toras durante a vaporização e fervura tem sido de considerável benefício para diminuição das rachaduras (Bootle ${ }^{8}, 1973$ citado por Edwards, 1973). Somente a fixação de cintas metálicas antes do traçamento também tem sido ineficiente, pois as mesmas tem que ser removidas antes de serrar as toras e não diminuem as rachaduras do material serrado (Villiers, 1973).

Provou-se matematicamente que cortes inclinados diminuem as rachaduras e aplicando-se uma técnica sofisticada de corte obteve-se bons resultados (Mattheck \& Walther, 1991), apesar dos inconvenientes operacionais (Mattheck \& Kubler, 1995).

\footnotetext{
${ }^{7}$ BOLZA, E; KLOOT, N.H. The mechanical properties of 174 Australian timbers. Adelaide: CSIRO, 1963. (Tech. Pap., 25)

${ }^{8}$ BOOTLE Comunicação pessoal. 1973.
} 
As toras devem ser extraídas e transportadas no maior comprimento possível (Haslet, 1988, 1990). A conversão das mesmas em madeira serrada o mais rápido possivel tem sido um dos métodos mais eficientes para diminuir perdas devido a rachaduras (Haslett, 1988, 1990 e Villiers, 1973).

O desdobro das toras deve ser planejado em função da obtenção de peças de qualidade compatível com sua utilização prática. Os cortes duplos e/ou múltiplos são os mais vantajosos para obtenção de peças com menor quantidade de distorções, sendo que uma peça curva poderá ser utilizada com vantagem se sua curvatura for usada como contra flecha numa estrutura (Garcia, 1995).

\subsubsection{Variações intra-árvores}

A variação das tensões na periferia da árvore nem sempre está relacionada com a tortuosidade (Nicholson et al., 1975) e inclinação do fuste (Kubler, 1987). O que realmente exerce influência sobre as variações periféricas nas tensões de crescimento é a reorientação da árvore (Boyd, 1980), principalmente se a reorientação for recente (Kubler, 1987).

Em E. regnans de 39 anos de idade, Chafe (1981) observou um aumento das tensões de crescimento até uma altura de 7,5 $\mathrm{m}$ na árvore. Yao (1979) medindo árvores de carvalho e freixo, cujos diâmetros variavam de 38 a $48 \mathrm{~cm}$ de DAP, observou que as tensões de crescimento culminavam a uma altura de aproximadamente $6,4 \mathrm{~m}$, declinando então até uma altura de $11 \mathrm{~m}$. Chafe (1985) estudando árvores de $E$ nitens variando de 19 a $25 \mathrm{~m}$ de altura, verificou que as tensões de crescimento longitudinais declinavam acentuadamente até uma altura de $3 \mathrm{~m}$, permanecendo constantes até $9 \mathrm{~m}$ e declinando até os $15 \mathrm{~m}$. O mesmo autor concluiu que esta distribuição sugere uma complexa, possivelmente sinuosa, distribuição das tensões e deformações de crescimento em relação à altura da árvore.

Skolmen (1974) analisando tensões em pranchas diamétricas de 25 toras de E. saligna aos 12 anos de idade, com árvores variando de 29 a $40 \mathrm{~m}$ de altura, 
concluiu que as tensões de crescimento diminuem de intensidade até uma altura de aproximadamente $11 \mathrm{~m}$. O mesmo autor calculou um coeficiente de correlação de 0,75 destas tensões com as rachaduras de topo e concluiu que ela foi um pouco baixa devido a inclusão de rachaduras oriundas da operação de derrubada e traçamento.

Em árvores variando de 19 a 31 m de altura, Purnell (1988) observou que a porcentagem total de rachaduras de topo, 6 semanas após o corte, decrescia até os $12 \mathrm{~m}$. Ele também observou que para as rachaduras com formato triangular havia um leve aumento de 0 a 2,4 m de altura. Deve-se observar que apesar destes valores terem um considerável efeito das tensões de secagem, possuem também um certo efeito de tensões de crescimento e da interação destas duas.

\subsubsection{Influência ambiental}

Se não houver um estímulo de reorientação, as deformações de crescimento permanecem constantes ao longo do tempo e portanto são as mesmas tanto no lenho primaveril como no outonal. Isto ocorre porque sendo as contrações longitudinais das células a origem das tensões de crescimento não existe razão destas mudarem conforme a estação do ano (Kubler, 1987). Entretanto alguns autores afirmam que as tensões de crescimento mudam conforme as estações do ano (Malan, 1984 e Mattheck \& Kubler, 1995).

O vento e outras forças externas impõem adicionais deformações de crescimento às árvores (Kubler, 1987; Bariska et al. ${ }^{9}, 1987$ citado por Malan, 1995). Árvores com maiores alturas (Malan, 1984, 1988a) ou com alta relação altura / diâmetro (Bariska et al., 1987 citado por Malan, 1995) desenvolvem maiores níveis de tensões de crescimento.

\footnotetext{
${ }^{9}$ BARISKA, M: KNUFFEL. W.E.; VAN RENSBURG, Z. Literature survey on selected properties of Eucalypts. Part 1 - Splitting, Brittleheart, Tree form and Bark stripability. s.l : CSIR. 1987. 43p. (Special Report, 62)
} 
Tratamentos silviculturais diminuem as deformações de crescimento num estudo de baguetas amostradas com trado de incremento em E. nitens (Ferrand, 1983) e E. grandis (Wilkins \& Kitahara, 1991b). Estes autores concluíram que existe uma forte relação destas deformações com o grau de competição entre árvores. Em outro trabalho, estudando as deformações longitudinais na periferia e no interior de árvores de E. grandis, Wilkins \& Kitahara (1991a) não encontraram correlação entre a deformação periférica de baguetas e a taxa de crescimento diametral, mas verificaram que o gradiente de deformações da medula para casca era menor em árvores com maiores taxas de crescimento.

O diâmetro das árvores foi inicialmente relacionado com o nível das tensões de crescimento (Malan, 1984), mas isto foi posteriormente contestado num experimento de $E$. grandis com 33 anos de idade, submetido a diferentes intensidades de desbaste (Malan, 1992).

Árvores remanescentes de povoamentos com espaçamento adensado desenvolvem altos níveis de tensões de crescimento após desbastes pesados para dar maior suporte mecânico no novo e exposto ambiente (Bariska et al., 1987 citado por Malan, 1995).

Lückhoff $^{10}, 1967$ citado por Hillis (1978) observou que o acentuado aumento das perdas de madeira serrada devido ao empenamento eram diretamente proporcional à intensidade de poda em árvores de 12 anos de E. grandis.

\subsubsection{Influência genética}

Conforme diversos autores (Fernandes, 1982; Kubler, 1987; Malan, 1984, 1987; Nicholson, 1973 e Ponce, 1993) a tensão de crescimento varia dentro das espécies e é herdável.

Malan (1987) obteve estimativas de herdabilidade de 0,52 e 0,70 no sentido restrito e de 0,75 no sentido amplo para rachaduras de topo usando o método de 
Conradie (1980) em dois experimentos de E. grandis aos 6 anos de idade. O autor comenta que apesar destes valores devem ser interpretados com certa cautela devido a seleção de famílias antes da amostragem e desbalanceamento do experimento, existe uma forte evidência de que as tensões de crescimento são herdáveis.

Harris (1989) concluiu que a grã espiralada, outra causa dos empenamentos e torções, tem mostrado estar sob considerável grau de controle genético. Villiers (1973) cita severas inclinações de grã espiralada para algumas espécies de eucalipto.

Quando a característica desejada é de difícil ou imprecisa medição, a seleção indireta pode ser é mais preferível que a seleção direta (Falconer, 1989). Isto porque os erros de medição reduzem a herdabilidade. Dessa forma, pode ser preferível do ponto de vista econômico, medir-se um caráter de mais fácil obtenção e que tenha correlação genética com a característica desejada. Destaca-se que a causa desta correlação genética pode ser tanto originada por efeitos pleiotrópicos dos genes quanto por falta de equilibrio de ligação (Vencovsky, 1987).

\subsubsection{Variação intraclonal}

Libby \& Jund (1962) concluíram que quando o efeito "c", o qual é influenciado pela topófise, é o principal componente de variação em diversas condições experimentais, então existe a possibilidade da estimativa dos parâmetros genéticos da população ser tendenciosa, superestimando o ganho predito na seleção clonal.

Destaca-se ainda que os efeitos da idade fisiológica não influenciam apenas o crescimento das plântulas e posteriormente das árvores formadas, mas também as características básicas da madeira. Tal fenômeno pode ser ilustrado na Figura 2, que mostra o efeito da ciclófise, ou seja, um processo de maturação do meristema apical (Olesen, 1978) numa característica da madeira. Na Figura 2(b) observa-se que uma árvore originada de um propágulo juvenil tende a reproduzir os mesmos ângulos de grã

${ }^{10}$ LÜCKHOFF, H.A.. Pruning of Eucalyptus grandis. For. S. Afr., v.8, p. 75-85, 1967. 
da árvore mãe. Em rametes derivados de ortetes maduros, os ângulos da grã no centro do tronco (anéis 2 e 3) são similares aos do ortete, mas nos anéis posteriores, a taxa de diminuição é muito menor e tende a se estabilizar, como mostra a Figura 2(a) num patamar ainda não explicado.
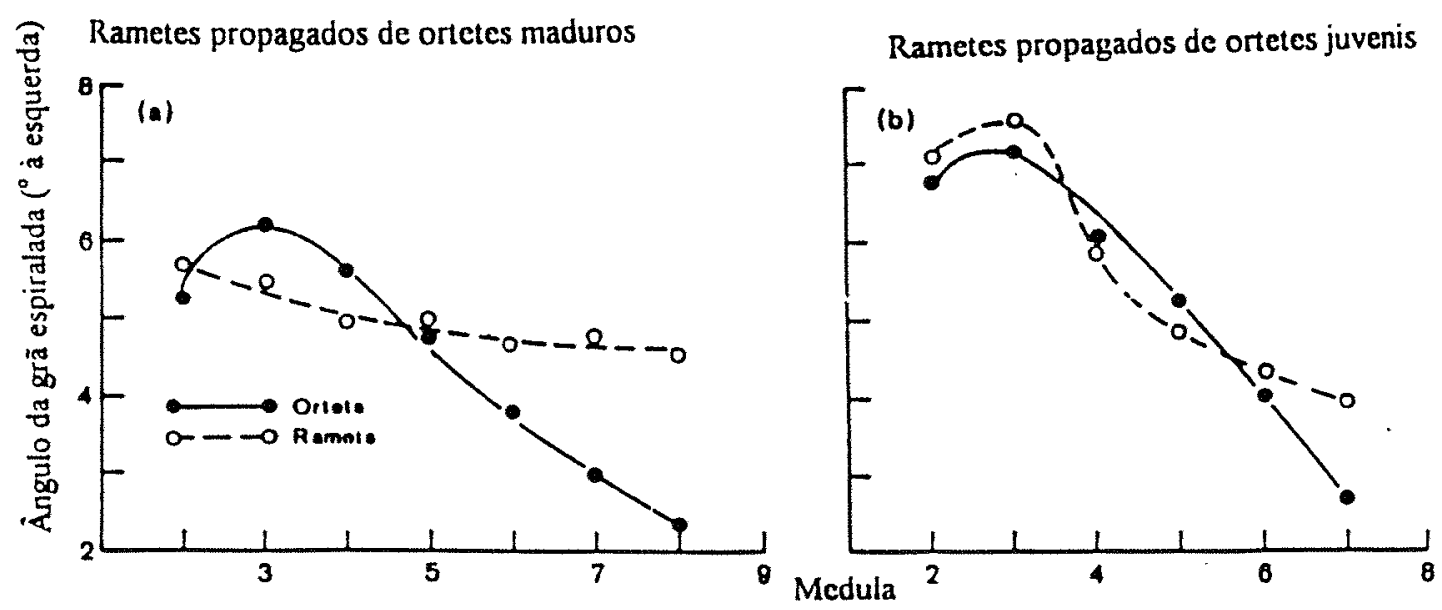

Número do anel de crescimento

Figura 2: Variação da grã espiralada dos anéis de crescimento da medula para casca em (a) rametes propagados de ortetes maduros e (b) rametes propagados de ortetes juvenis (Nicholls et al., 1977). 


\title{
3 VARIAÇÃO DE RACHADURAS DE TOPO EM TORAS DE Eucalyptus urophylla: UMA INVESTIGAÇÃO METODOLÓGICA
}

\author{
Lothar Schacht \\ José Nivaldo Garcia \\ Carlos Tadeu dos Santos Dias
}

\subsection{Resumo}

Um rápido e melhorado método de avaliação de rachaduras de extremidade de toras foi aplicado em 20 árvores de 9 anos de idade de Eucalyptus urophylla S.T.Blake para quantificarem-se as influências do clone, posição no fuste, tempo e condições de secagem. Encontrou-se uma alta correlação na intensidade das rachaduras entre faces adjacentes, fato este que possibilitou o estudo das condições de secagem das extremidades das toras. Verificou-se uma altíssima intensidade de rachadura nas extremidades expostas à secagem livre quando comparada com aquela observada nas extremidades protegidas, o que permite concluir que grande parte das rachaduras de extremidades de toras é devida à interação das tensões de crescimento com as de secagem. Verificou-se ainda uma significativa diminuição da intensidade das mesmas com o aumento da altura ao longo do fuste da árvore.

Palavras Chave: Eucalyptus, Tensão de Crescimento, Rachadura de Topo, Tensão de Secagem, Colapso. 


\subsection{Summary}

A quick and improved method to evaluate the end splitting of logs was applied to 20 trees 9 years old of Eucalyptus urophylla S.T.Blake in order to quantify the influence of clone, position in the stem, time and drying conditions. A high correlation in the intensity of splits between adjacent faces was found, wich allowed the study of the drying conditions on the log ends. A very high splitting intensity was verified when the $\log$ end was exposed to free drying, in comparison with the protected log end. This allow infering that a great part of the log end splits arise from the interaction of growth and drying stresses. A significant reduction of the log end splits along the stem from the bottom to the top was also verified.

Key Words: Eucalyptus, Growth Stress, End Splitting, Drying Stress, Collapse.

\subsection{Introdução}

Os métodos de avaliação das rachaduras de topo de toras iniciaram-se pela medição do aumento da circunferência na sua extremidade após o secionamento (Villiers, 1973). Eles evoluíram pela inclusão de rachaduras que não atingiam a borda da seção de corte com o método de Conradie (1980), pelo cálculo da proporção das rachaduras (Wilson, 1985), ou simplesmente pela medição do comprimento das rachaduras na seção de corte (Bariska 1990).

Quando uma árvore é derrubada e cortada em toras as tensões de crescimento são parcialmente liberadas, podendo causar rachaduras. Isto ocorre porque o traçamento causa principalmente a redistribuição e transformação da tensão longitudinal em tensão transversal e de cisalhamento (Wilhelmy \& Kubler, 1973).

Podem-se distinguir 5 tipos de rachaduras que degradam a madeira, sendo que dois são resultantes das tensões de crescimento (rachaduras de cerne e laterais), um é conseqüência da operação de derrubada da árvore e os outros dois são oriundos do processo de secagem (rachaduras de colapso e de secagem)(Bariska, 1990). 
As rachaduras são conseqüência de um fenômeno complexo, porque os vários tipos de rachaduras interagem entre si e são dependentes do tempo para a sua manifestação. Kubler (1987) revisou vários trabalhos sobre o desenvolvimento decrescente das rachaduras de topo em toras. Marder (1997) explica fisicamente o desenvolvimento das rachaduras através de três fases e a sua superfície rugosa pela inconstante velocidade de propagação.

A idade fisiológica do material propagado vegetativamente deve ser considerada, porque ela influência a taxa de crescimento das plantas (Watt, 1995) e as propriedades básicas da madeira (Lausberg et al., 1995; Nicholson et al., 1977 e Sweet \& Harris, 1976).

O objetivo deste estudo foi verificar a real importância de fatores como a posição de altura no fuste e as condições de secagem na intensidade de rachaduras de topo em toras de Eucalyptus urophylla S.T.Blake. Conduziu-se um experimento padrão para evitar distúrbios colaterais e obter confiabilidade na predição dos efeitos clonais.

\subsection{Material e métodos}

Estudaram-se as rachaduras de topo em 5 clones x 4 árvores (20 árvores no total), em um banco clonal de E. urophylla situado no município de Aguaí, estado de São Paulo. Este material, originário da llha de Flores (Indonésia), tinha sido selecionado com certa predominância para casca lisa e propagado a partir de estacas de uma população base de 6 anos de idade.

O banco clonal apresentou no momento da avaliação, aos 9 anos de idade, uma grande variação intraclonal no diâmetro das árvores, cuja causa primária pode em grande parte ser atribuída à idade fisiológica. Quando esta é determinada pela posição no ortete e é mantida nos rametes propagados, o efeito é conhecido como sendo de topófise (Dodd \& Power, 1989). Para diminuir os prováveis efeitos da topófise sobre as caracteristicas da madeira, selecionarem-se somente as maiores árvores em cada parcela. 
Após a derrubada, as árvores foram traçadas em toras de $3,4 \mathrm{~m}$ a partir de $1,3 \mathrm{~m}$ da base. Os fustes das árvores que caíram sobre obstáculos ou os que não estavam bem apoiados no solo foram descartados, evitando-se assim rachaduras devido ao impacto da queda ou de tensões de flexão durante o seccionamento.

Para a avaliação das rachaduras de topo das toras adotou-se o mesmo princípio proposto por Wilson (1985), modificando-se apenas o critério de medição do comprimento das mesmas com o intuito de otimizar o tempo de medição. As rachaduras com formato retangular, trapezoidal, ou elíptico foram consideradas como duas rachaduras triangulares adjacentes.

Agruparam-se as rachaduras em 4 classes de comprimento, com base na distância que elas alcançavam a partir da medula, no plano da seção transversal. Estas classes são as seguintes:

\begin{tabular}{clc}
\hline Classe & Comprimento das rachaduras & Peso \\
\hline 1 & iguais ao raio da seção transversal & 1.00 \\
2 & menores que o raio, mas maiores que $3 / 4$ deste & 0.75 \\
3 & menores que $3 / 4$ do raio, mas maiores que $1 / 2$ deste & 0.50 \\
4 & menores que $1 / 2$ do raio, mas maiores que $1 / 4$ deste & 0.25 \\
\hline
\end{tabular}

Em cada seção transversal calculou-se uma porcentagem estimada de rachaduras (SEP) pela seguinte equação:

$$
\mathrm{SEP}=\frac{\left(\sum A_{i} p_{i}\right) \cdot 100}{\pi \cdot D}
$$

onde:

$$
\begin{aligned}
& A_{i}=\text { máxima abertura da rachadura pertencente à classe de comprimento } i(i=1, \ldots, 4) ; \\
& p_{i}=\text { peso da rachadura da classe } i \\
& D=\text { diâmetro médio da seção transversal, livre de rachaduras. }
\end{aligned}
$$


O fuste das árvores foi secionado nas alturas de 1,$3 ; 4,7 ; 8,1$ e $11,5 \mathrm{~m}$, onde aplicaram-se os seguintes tratamentos:

1) Testemunha (t)

2) Selante a base de cera (s)

3) Saco plástico umedecido (p)

4) Saco plástico umedecido + selante a base de cera (m)

O cálculo do SEP para estes 4 tratamentos resultou respectivamente nos caracteres RT, RS, RP e RM.

Em cada altura de corte sorteou-se um dos 4 tratamentos, de modo que um clone não recebesse o mesmo tratamento na mesma posição de altura. A face de cada seção transversal foi amostrada aleatoriamente para cada tratamento.

Faces adjacentes que não receberam qualquer tratamento também permaneceram como tratamento testemunha (RT), para o qual também calculou-se o coeficiente de correlação de Pearson entre o topo de uma tora e a base da tora seguinte (faces adjacentes).

O modelo linear que permitiu estudar as diversas fontes de variação em um determinado tempo foi:

$$
Y_{i j k l}=m+c_{i}+a_{j(i)}+p_{k}+t_{l}+(c p)_{i k}+(c t)_{i l}+(p t)_{k l}+e_{i j k l}
$$

onde:

$\mathrm{Y}_{\mathrm{ijk1}}$ : valor do tratamento $\mathrm{l}$, na altura $\mathrm{k}$, da árvore $\mathrm{j}$, dentro do clone $\mathrm{i}$;

m : a média da população;

$c_{i}$ : efeito aleatório do clone $\mathrm{i}(\mathrm{i}=1,2, \ldots 5)$;

$a_{j(i)}$ : efeito aleatório da árvore $\mathrm{j}$, dentro do clone $\mathrm{i}(\mathrm{j}=1,2,3,4)$;

$p_{k} \quad$ : efeito fixo da altura $k(k=1,2,3,4)$;

$t_{1}$ : efeito fixo do tratamento $1(1=1,2,3,4)$; 
$(\mathrm{cp})_{\mathrm{ik}}$ : efeito aleatório da interação do clone i com a altura k;

$(\mathrm{ct})_{\mathrm{il}}$ : efeito aleatório da interação do clone i com o tratamento l;

$(\mathrm{pt})_{\mathrm{kl}}$ : efeito fixo da posição $\mathrm{k}$ com o tratamento l;

$\mathrm{e}_{\mathrm{ijkl} \mathrm{I}}$ : efeito aleatório do erro.

As rachaduras foram medidas, em todas as seções transversais, diariamente até o $4^{0}$ dia e no $6^{0}$ dia. Nas faces que receberam o saco plástico como tratamento mediram-se também as rachaduras no $22^{\circ}$ dia. Acompanhou-se também as condições de secagem, medindo-se as temperaturas dos bulbos seco e úmido às 14:00 $\mathrm{h}$, o que permitiu calcular o déficit de pressão do vapor de água no ar (D).

Em todos os dados de SEP utilizou-se da transformação potência de Box e Cox (1964) para analisar a significância dos testes F, das correlações e das comparações múltiplas pelo teste de Tukey.

\subsection{Resultados e discussão}

Encontraram-se correlações para rachaduras RT de faces adjacentes de $0.73(\mathrm{P}=0.0003)$ e $0.75(\mathrm{P}=0.0001)$ no $4^{\mathrm{Q}}$ e $6^{\circ}$ dia após o traçamento, respectivamente. Estes valores são coerentes aos encontrados por Purnell (1988), o qual encontrou na $6^{\mathbf{a}}$ semana correlação positiva $(0.50<\mathrm{r}<0.90, \mathrm{P}<0.01)$ entre faces adjacentes aos $2,4 \mathrm{~m} \mathrm{e}$ $4,8 \mathrm{~m}$ de altura da árvore. Esta correlação é muito importante porque permite compararem-se dois tratamentos diferentes numa mesma altura e principalmente numa mesma árvore, com grande economia de tempo e material de ensaio por evitarem-se as influências conseqüentes das variações existentes entre posições e indivíduos. Observouse também que os valores encontrados não foram maiores devido à presença de nós.

Na Figura 3 os pontos de RT e RP são médias de 4 medidas de SEP relativas a um clone, sempre de faces adjacentes, relativos as 4 posições de altura, sendo que D foi plotado no mesmo eixo do SEP, mas em centímetros de mercúrio. Verificouse um pronunciado efeito da secagem no desenvolvimento das rachaduras, devido ao 
fato da intensidade das rachaduras de faces adjacentes estarem altamente correlacionadas. Este mesmo efeito também foi observado por Bariska (1990).

Na Figura 3 verifica-se também que a diminuição de $\mathrm{D}$ após o $4^{\circ}$ dia pode explicar a decrescente taxa de variação do SEP, medido especificamente no tratamento RT.

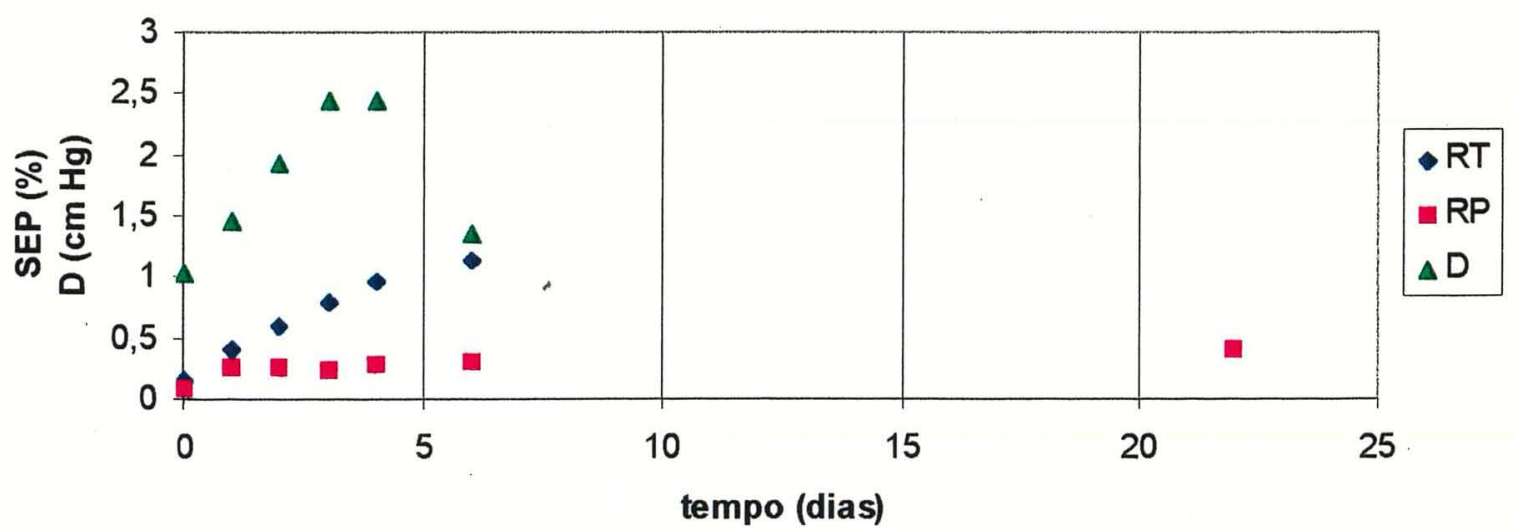

Figura 3: Desenvolvimento das rachaduras de topo das toras após o secionamento.

A Tabela 1 mostra diferenças altamente significativas entre $\mathrm{C}, \mathrm{P}$ e $\mathrm{T}$ nos dois tempos estudados. A interação $\mathrm{C} \times \mathrm{T}$ apresentou efeito significativo somente no $4^{\underline{0}}$ dia de medição. A ausência de significância do efeito $\mathrm{A} / \mathrm{C}$ confirma que a seleção das maiores árvores dentro de cada parcela foi acertada, pois eliminaram-se eventuais consequências do efeito "c". A ausência de significância da interação P x C indica que para os clones estudados existe um determinado padrão de intensidade de rachaduras ao longo do fuste.

As rachaduras de topo de toras cobertas com saco plástico (RP) podem ser consideradas como resultado exclusivo da liberação das tensões de crescimento, pois os sacos plásticos permaneciam úmidos durante as medições. 
Tabela 1: Análise de variância de SEP no $4^{\circ}$ e $6^{\circ}$ dia de medição:

\begin{tabular}{lccc}
\hline Fonte de Variação & GL & $\operatorname{Pr}>\mathrm{F}\left(4^{\circ} \text { dia }\right)^{11}$ & $\operatorname{Pr}>\mathrm{F}\left(6^{\circ} \text { dia }\right)^{11}$ \\
\hline $\mathrm{C}$ & 4 & 0.0025 & 0.0001 \\
$\mathrm{~A} / \mathrm{C}$ & 15 & 0.7145 & 0.4206 \\
$\mathrm{P}$ & 3 & 0.0032 & 0.0011 \\
$\mathrm{~T}$ & 3 & 0.0001 & 0.0001 \\
$\mathrm{C} \times \mathrm{P}$ & 12 & 0.0658 & 0.0586 \\
$\mathrm{C} \times \mathrm{T}$ & 12 & 0.0389 & 0.0619 \\
$\mathrm{P} \times \mathrm{T}$ & 9 & 0.6465 & 0.4596 \\
Erro & 79 & & \\
\hline
\end{tabular}

Obs.: $\mathrm{C}=$ clones, $\mathrm{A}=$ árvores, $\mathrm{P}=$ posições, $\mathrm{T}=$ tratamentos.

A Figura 4 mostra as médias com os respectivos desvios padrões para todos os tratamentos e posições de altura no $4^{\underline{\underline{0}}}$ dia após o traçamento. A diferença entre $a$ intensidade de rachaduras nos tratamentos que receberam saco plástico (tratamentos $\mathrm{p}$ e m) comparada com as que não o receberam (tratamentos t e s) foi aproximadamente de duas a três vezes menor, o que é considerado suficiente para supor que existe uma forte interação entre a secagem e a tensão de crescimento. Se considerarmos que as rachaduras de secagem geralmente começam após o $4^{0}$ dia (Bariska, 1990), enquanto as de colapso já podem começar 20 minutos após o traçamento (Barnacle, 1971), então esta grande diferença é devida ao colapso e/ou interação deste com as tensões de crescimento.

"Os graus de liberdade e o nível de probabilidade foram baseados na aproximação de Satterthwaite. 

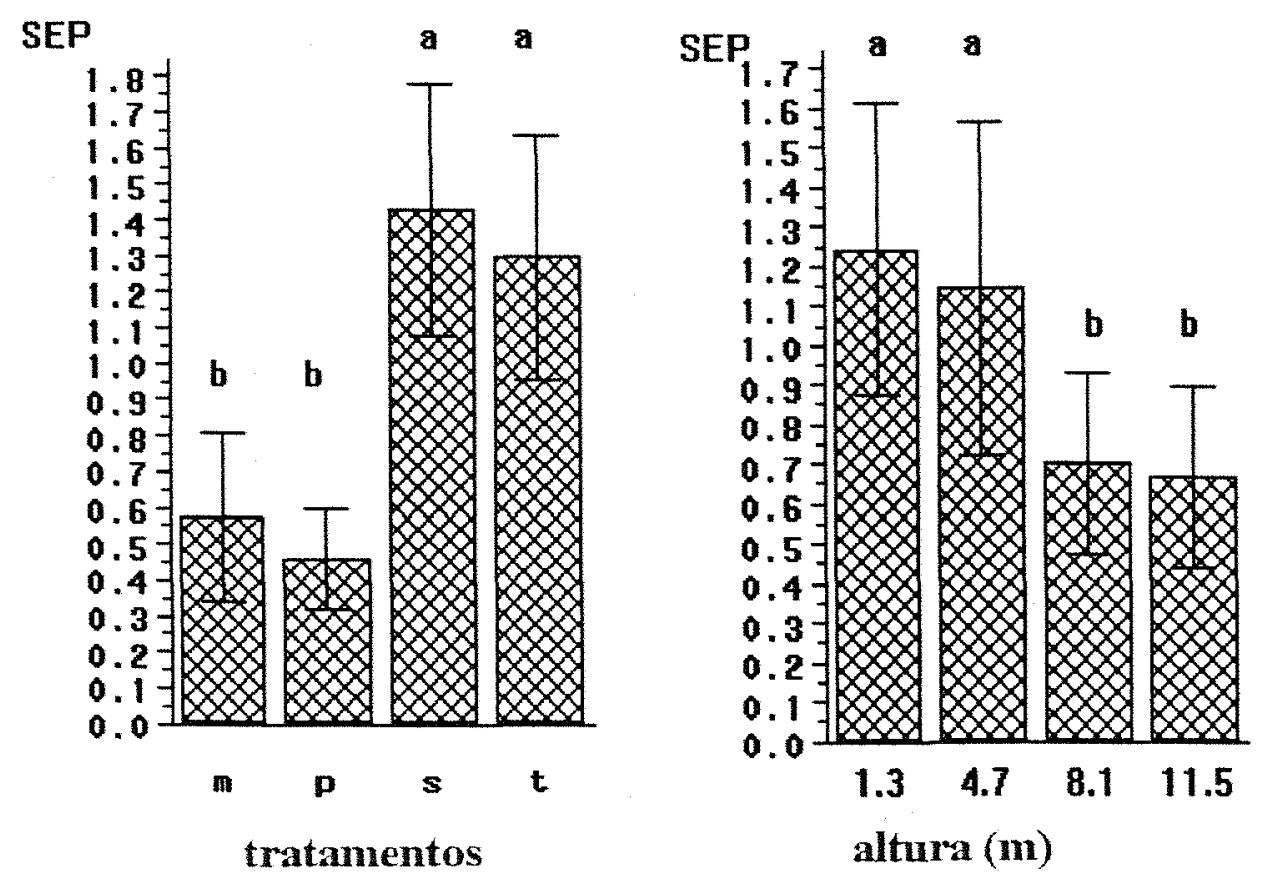

Figura 4: Diferenças das médias de SEP para cada tratamento e posição de altura no fuste da árvore.

A aplicação de selante a base de cera no topo da tora não mostrou qualquer beneficio na diminuição das rachaduras quando comparado com o tratamento testemunha.

A Figura 4 também mostra que as rachaduras de topo de toras são maiores nas alturas de 1,3 e 4,7 $\mathrm{m}$ do solo, do que nas de 8,1 e 11,5 m. Esta tendência também foi observada por Purnell (1988).

\subsection{Agradecimentos}

Os autores agradecem a Champion Papel e Celulose Ltda pelo total apoio na coleta de dados em campo. Agradecem também ao Dr. François S. Malan e ao Eng. Luis Maria Salvarrey pelas sugestões preliminares. 


\title{
4 VARIAÇÃO GENÉTICA DE INDICADORES DE TENSÃO DE CRESCIMENTO EM CLONES DE Eucalyptus urophylla
}

\author{
Lothar Schacht \\ José Nivaldo Garcia \\ Roland Vencovsky
}

\subsection{Resumo}

Num banco clonal com 9 anos de idade de Eucalyptus urophylla S.T.Blake, 148 árvores de 27 clones foram derrubadas e serradas para o estudo da variação genética de indicadores de tensão de crescimento. Caracteres relativos à tensão de crescimento como rachaduras de toras, de tábuas, empenamentos da madeira serrada e caracteres silviculturais como diâmetro à altura do peito sem casca (DAP), altura total da árvore (HT), altura do fuste, comprimento de copa e conicidade do fuste foram considerados para estimarem-se as herdabilidades no sentido amplo e as correlações genéticas e fenotípicas entre os caracteres. Os resultados mostram que as rachaduras e os empenamentos de toras e/ou madeira serrada são altamente herdáveis e que não existe correlação genética entre DAP e qualquer um destes caracteres de qualidade da madeira. A porcentagem de rachaduras de topo de toras, a flecha da primeira costaneira ou a flecha do vigote desta, obtidas em condições padronizadas, são caracteres adequados para seleção que podem melhorar simultaneamente as rachaduras e empenamentos da madeira serrada. A significativa correlação negativa obtida das rachaduras e empenamentos com o quociente DAP/HT, chamado fator de estabilidade, possibilita também o melhoramento destes caracteres através de seleção indireta, com a vantagem de ser um indicador não destrutivo. 
Palavras chave: Tensão de Crescimento, Rachadura de Topo, Empenamento, Madeira Serrada, Eucalyptus, Herdabilidade, Correlação Genética.

\subsection{Summary}

In a 9 years old clonal bank of Eucalyptus urophylla S.T.Blake, 148 trees of 27 clones were felled and sawed for studying the genetic variation of growth stress indicators. Traits concerning growth stress as log end splitting, end boards splitting and lumber warping were taken in several positions along the tree stem and some silvicultural traits as diameter at breast height within bark (DBH), total height of the tree (THT), crown length and stem tapering were considered for estimating broad sense heritabilities, genetic and phenotypic correlation. The results showed that splits and warping of logs and/or saw lumber are highly heritable and there is no genetic correlation between $\mathrm{DBH}$ and any of these wood quality characters. The log end splitting percentage, the deflection of the first slab or the deflection of the beam cut from it, obtained by standard conditions, are very good characters for selection which can improve simultaneously the splits and warping of the saw lumber. The significant negative correlation of the DBH/THT, called stability factor, with the splits and warping also allows the improvement of these traits by indirect selection, with the advantage of being a non destructive indicator.

Key Words: Growth Stress, End Splitting, Warping, Lumber, Eucalyptus, Heritability, Genetic Correlation.

\subsection{Introdução}

As rachaduras e empenamentos da madeira serrada estão entre os principais problemas que afetam a qualidade e o rendimento em madeira serrada do eucalipto e que têm como causa fundamental as tensões de crescimento.

São poucos os trabalhos que quantificam os efeitos genéticos das tensões de crescimento (Fernandes 1982 e Malan, 1984, 1987), ou apenas comentam da existência destes efeitos (Haslett, 1988a; Nicholson, 1973; Ponce, 1993 e Zobel \& Jett, 
1995). Embora os eucaliptos auto desenvolvem, em geral, elevados niveis de tensões de crescimento, algumas de suas espécies, como por exemplo E. muellerana, apresentam fracos indícios destas tensões (Haslett, 1988a).

A existência do "efeito c" têm sido apontada como causa de estimativas tendenciosas de parâmetros genéticos (Burdon \& Shelbourne, 1974 e Libby \& Jund, 1962). Quando este efeito é causado por diferenças de idade fisiológica, estas podem estar associadas às variações na taxa de crescimento (Watt et al., 1995) e nas propriedades básicas da madeira (Lausberg et al., 1995; Nichols et al., 1977 e Sweet \& Harris, 1976).

As tensões de crescimento podem ter grandes variações periféricas na árvore, isto pode ser explicado pela inclinação do fuste (Nicholson, 1973), ou outros fatores relacionados à presença de madeira de reação (Jourez, 1997 e Walker, 1993), tornando estas tensões diversas vezes maiores que na madeira normal (Jacobs, 1945). Porém, árvores em que certa tortuosidade permaneceu constante durante vários anos, estas variações periféricas são menores (Nicholson et al., 1975). A variação na intensidade de manifestação destas tensões ao longo da altura do fuste tem sido controvertida. Pode ser crescente até uma altura de cerca de $7 \mathrm{~m}$ (Chafe, 1981 e Yao, 1979) com posterior declínio até os $11 \mathrm{~m}$ (Yao, 1979), decrescente até os 11 ou $12 \mathrm{~m}$ (Purnell, 1988 e Skolmen, 1974), sempre crescente, ou mesmo invariante conforme diversas citações de Kubler (1987).

Com o objetivo principal de investigar as variações genéticas, fenotípicas, intraclonais e intra-árvores de indicadores de tensões de crescimento, surgiu o interesse em estudar um banco clonal de Eucalyptus urophylla S. T. Blake, visto que esta espécie tem apresentado um dos menores índices de rachaduras no seu híbrido com o E. grandis (Malan, 1993) e um dos menores índices de empenamento (Garcia, 1992). 


\subsection{Material e métodos}

Os estudos foram realizados sobre um banco clonal de 21,4 ha situado na região de Aguaí, Estado de São Paulo, onde procedeu-se um estudo da variação genética de vários caracteres tecnológicos, utilizando-se para isto 148 árvores.

O material, selecionado com certa predominância para casca lisa, foi propagado por estacas a partir de uma população base de 6 anos de idade, originária da Ilha de Flores (Indonésia).

Selecionaram-se sistematicamente todos os clones com, no mínimo, duas parcelas e DAP (diâmetro à altura do peito) médio das árvores superior a $15 \mathrm{~cm}, 0$ que resultou num desbalanceamento dos dados, pois 20 clones dos 27 selecionados continham 3 repetições e os outros 7 clones continham apenas 2 repetições. No momento da avaliação, aos 9 anos de idade, o material de estudo apresentou grande variação intraclonal do diâmetro, o que foi contornado pela seleção de apenas duas árvores de maior DAP dentro de cada parcela, com o intuito de diminuir os efeitos de idade fisiológica, provavelmente de topófise.

A seleção das parcelas de 4 X 10 árvores, dentro de cada clone, obedeceu ao critério do menor número de falhas e descarte das árvores de bordadura em cada parcela.

No momento do corte das árvores, coletaram-se vários caracteres dendrométricos além do DAP sem casca (DS) e altura total da árvore (HT). A altura do fuste (HF) foi medida até a altura que tivesse no mínimo $3 / 4$ da circunferência da copa viva, ou fosse a média desta com a altura que tivesse aproximadamente a metade da circunferência com copa viva. A copa (CP) foi calculada porcentualmente em relação a $\mathrm{HT}$, ou seja, pela fórmula (HT-HF)/HT, 100. A conicidade do fuste $(\mathrm{CN})$ foi calculada pela razão da circunferência a 0,005 . HT com a circunferência a 1/3 de HT. Determinouse também um fator de estabilidade ST através da razão D/HT.

No secionamento das árvores em toras de $3,4 \mathrm{~m}$, o qual foi a partir de $1,3 \mathrm{~m}$ de altura, apoiou-se corretamente as árvores para evitarem-se rachaduras devidas 
às tensões de flexão. Esta operação ocorreu num mesmo dia, para evitarem-se diferenças nas rachaduras devidas ao fator tempo pós corte (Bariska, 1990 e Schacht \& Garcia, 1997).

As árvores que, durante o corte de derrubada, caíram sobre tocos ou troncos de outras árvores eram descartadas e neste caso cortava-se uma terceira árvore na parcela. Dentro da amostragem básica de 148 árvores selecionaram-se ainda as 60 árvores que apresentaram maior retidão de fuste e das quais foi cortada uma segunda tora para proceder a análise da variação vertical de alguns caracteres. Dessa forma foi possivel estudar a variação vertical das rachaduras de extremidades de toras (RP) em 6 clones, das rachaduras de tábuas (TB) em 12 clones e do empenamento (V) em 10 clones. As variáveis RP, TB e V serão descritas adiante, conjuntamente com as demais.

Imediatamente após o secionamento, os topos das toras foram vedados com um saco plástico umedecido para retardar as rachaduras de secagem, e assim as toras foram conservadas até o momento do desdobro.

As rachaduras do topo das toras foram medidas no $4^{\underline{0}}$ dia após o secionamento, conforme a metodologia no Capítulo 3. Em todas as árvores mediram-se as rachaduras com o topo das toras coberto com saco plástico (RP) e sem o mesmo (RT), na base da primeira tora e da face adjacente. Da mesma forma, nas árvores em que se cortou uma $2^{\underline{a}}$ tora, mediram-se as rachaduras $R P$ no topo da $1^{\underline{a}}$ e $2^{\underline{a}}$ tora.

Após a medição do diâmetro de topo das toras, fez-se um corte transversal na base de todas elas, padronizando-se o comprimento em $3,2 \mathrm{~m}$.

O primeiro e segundo cortes longitudinais das toras foram realizados numa serra de fita simples da Serraria do Departamento de Ciências Florestais da ESALQ, em Piracicaba. O primeiro foi feito como mostra a Figura 5(a) aproximadamente paralelo à casca, de modo a produzir uma costaneira de espessura aproximadamente constante de $3 \mathrm{~cm}$ sem casca, e segundo o plano de menor curvatura da tora para evitar-se o efeito da tortuosidade no valor do seu empenamento (Dinwoodie, 1966). Quando não foi possivel obter-se uma espessura constante, 
manteve-se aquela espessura no ponto mais fraco, geralmente na parte mediana, da costaneira resultante.

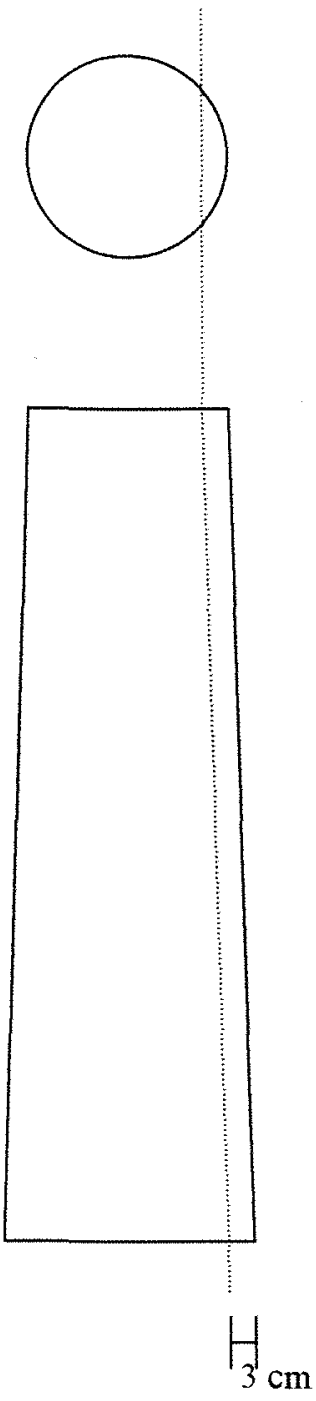

(a)

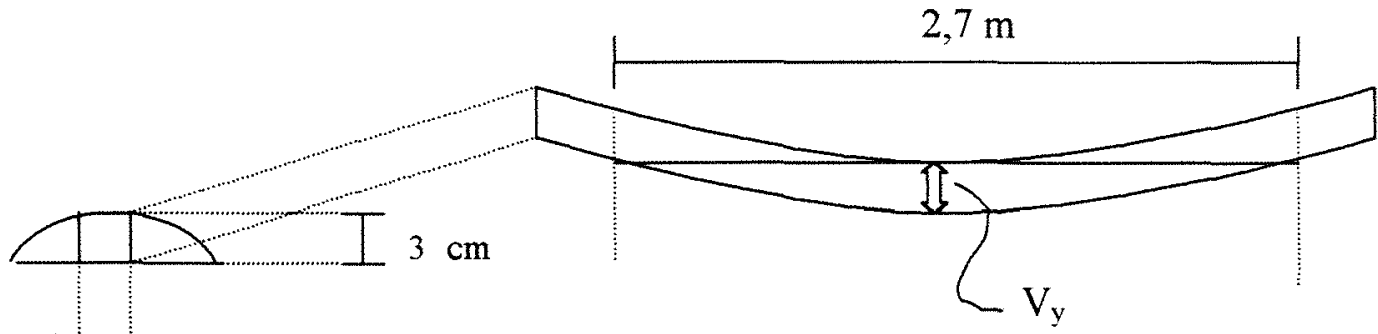

1

$2,5 \mathrm{~cm}$

(b)

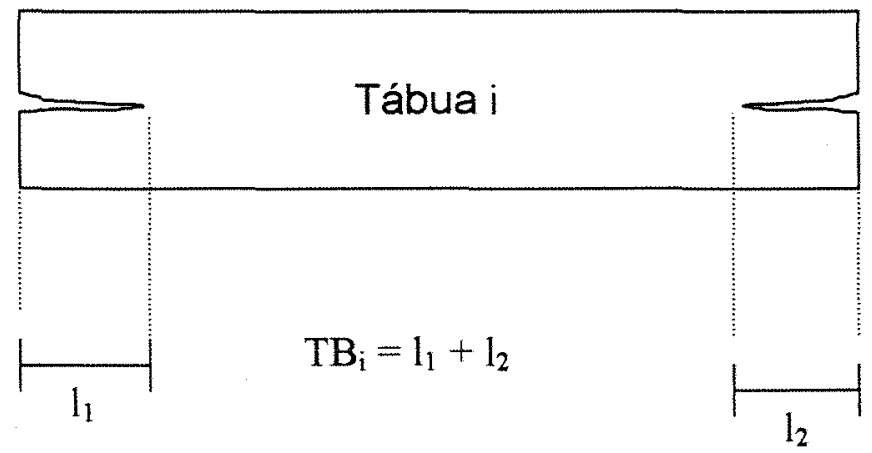

(c)

Figura 5: Processo de obtenção da costaneira (a), da viga central da mesma (b) e da medição do comprimento das rachaduras da tábua (c). 
Imediatamente após a obtenção, cada costaneira foi processada numa serra circular dupla, de maneira a produzir uma peça central chamada vigote da costaneira, de cerca de $2,5 \mathrm{~cm}$ de espessura como mostra a Figura 5(b). O encurvamento ou flecha da primeira costaneira $(\mathrm{F})$ e do vigote desta foram imediatamente medidos no meio dos seus $2,7 \mathrm{~m}$ internos, pois a flecha tem sido um bom indicador do nível de tensões de crescimento na árvore (Guéneau ${ }^{12}$, 1973 citado por Garcia, 1992 e Garcia 1995). A flecha resultante do vigote da costaneira (V) foi determinada pela resultante da medição das flechas componentes, dada pela fórmula: $V=\left(V_{x}{ }^{2}+V_{y}{ }^{2}\right)^{0,5}$. Depois de feito isto em todas as toras cortou-se a segunda costaneira oposta equivalente.

Os blocos resultantes foram imediatamente processados com cortes múltiplos e simultâneos para uma liberação simétrica das tensões de crescimento (Boyd, 1950; Dinwoodie, 1966; Garcia, 1995; Page, 1978 e Villiers, 1973) numa serra francesa em tábuas de 2,7 cm de espessura, na Serraria do IPT, na cidade de São Paulo. Antes deste processamento mediram-se, nas faces serradas do bloco, os comprimentos longitudinais máximos das rachaduras das duas extremidades (BL). Nas tábuas obtidas destes blocos também foram medidos os comprimentos máximos das rachaduras das duas extremidades, conformé mostra a Figura 5(c), e o encurvamento foi medido no ponto de flecha máximo. A partir destes dados calcularam-se as médias dos caracteres TB e E para cada bloco, respectivamente.

Durante a estocagem no pátio da serraria, no processamento e medição das toras, blocos e tábuas, procurou-se manter a umidade de saturação natural deste material com auxílio de aspersão com água e de lona plástica.

Os modelos estatísticos utilizados na análise dos dados foram:

$$
\begin{aligned}
& Y_{i j k}=m+c_{i}+p_{j(i)} \\
& Y_{i j k q}=m+c_{i}+p_{j(i)}+a_{k(i j)}+s_{q}+(c s)_{i q}+e_{i j q}+d_{i j k q} \\
& \text { onde: }
\end{aligned}
$$

\footnotetext{
${ }^{12}$ GUÉNEAU, P. Contraintes de croissance. Cahiers Scientifiques, v.3, p.1-52. Nogent-Sur-Marne, 1973.
} 
$\mathrm{Y}_{\mathrm{ijk}}$ : é o valor do caracter $\mathrm{Y}$ da árvore $\mathrm{k}$, na parcela $\mathrm{j}$, dentro do clone $\mathrm{i}$;

$\mathrm{Y}_{\mathrm{j} j \mathrm{jq}}$ : é o valor do caracter $\mathrm{Y}$ da seção $\mathrm{q}$, da árvore $\mathrm{k}$, dentro da parcela $\mathrm{j}$ do clone $\mathrm{i}$;

$\mathrm{m}$ : é a média;

$\mathrm{c}_{\mathrm{i}}$ : é o efeito aleatório do clone $\mathrm{i}$, sendo $\mathrm{i}=1,2, \ldots 27$;

$\mathrm{p}_{\mathrm{j}(\mathrm{i})}$ : é o efeito aleatório da parcela $\mathrm{j}$ dentro do clone $\mathrm{i}$, sendo $\mathrm{j}=1,2,3$;

$a_{k(i j)}$ : é o efeito aleatório da árvore $k$ dentro da parcela $\mathrm{j}$ do clone $\mathrm{i}$, sendo $\mathrm{k}=1,2$;

$\mathrm{s}_{\mathrm{q}} \quad$ : é o efeito fixo da seção de altura $\mathrm{m}$, sendo $\mathrm{q}=1,2,3$ para rachadura de topo, $\mathrm{q}$ $=1,2$ para flecha;

(cs) $)_{\mathrm{iq}}$ : é o efeito aleatório da interação do clone i com a seção de altura q;

$\mathrm{e}_{\mathrm{ijq}}$ : é o efeito aleatório do erro ao nível de parcelas e seções;

$\mathrm{d}_{\mathrm{ijkq}}$ : é o efeito aleatório do erro ao nível de árvores e seções.

Adotou-se o modelo aleatório [1] para a análise da variância e das correlações ao nível de totais de parcelas para todos os caracteres, um a um. Para o estudo da variação de RP, TB e V entre e dentro de árvores, adotou-se o modelo [2], que é misto, pois seções de altura (S) foram consideradas de efeito fixo e clones (C), parcelas (P) e árvores (A) foram considerados de efeitos aleatórios. Deve-se destacar que somente $\mathrm{C}$ x S é interação e que $\mathrm{S} \times \mathrm{P} / \mathrm{C}$ e $\mathrm{S} \times \mathrm{A} / \mathrm{P} / \mathrm{C}$ são, na verdade, erros. As diversas correlações entre as diversas variáveis estudadas foram obtidas através do procedimento de análise de covariância proposto por Kempthorne (1969).

O modelo [1] é um simples hierárquico, analisado somente em uma seção de altura na árvore. Já o modelo [2] refere-se a um delineamento em parcelas subdivididas, onde o fator principal refere-se aos efeito de clones, parcelas e árvores e o fator secundário refere-se às seções de altura, sendo que o primeiro fator é ao mesmo tempo analisado de forma hierárquica.

O esquema da análise de variância entre e dentro das árvores é apresentado na Tabela 2. Na determinação dos testes estatísticos, quando houve combinações linear de quadrados médios o número de graus de liberdade foi obtido pela aproximação de Satterthwaite (Barbin, 1993). 
Tabela 2: Esquema da análise de variância entre e dentro das árvores.

\begin{tabular}{|c|c|c|c|}
\hline № & Fonte de Variação & GL & Esperança do Quadrado Médio \\
\hline 1 & $\mathrm{C}$ & $\mathrm{I}-1$ & $\sigma_{d}^{2}+K \sigma_{e}^{2}+J K \sigma_{c s}^{2}+Q \sigma_{a}^{2}+K Q \sigma_{p}^{2}+J K Q \sigma_{c}^{2}$ \\
\hline 2 & $\mathrm{P} / \mathrm{C}$ & $\mathrm{I}(\mathrm{J}-1)$ & $\sigma_{d}^{2}+K \sigma_{e}^{2}+Q \sigma_{a}^{2}+K Q \sigma_{p}^{2}$ \\
\hline 3 & $\mathrm{~A} / \mathrm{P} / \mathrm{C}$ & $\mathrm{IJ}(\mathrm{K}-1)$ & $\sigma_{d}^{2}+Q \sigma_{a}^{2}$ \\
\hline 4 & $\mathrm{~S}$ & Q-1 & $\sigma_{d}^{2}+K \sigma_{e}^{2}+J K \sigma_{c s}^{2}+I J K \phi_{s}$ \\
\hline 5 & $\mathrm{~S} \times \mathrm{C}$ & $(\mathrm{Q}-1)(\mathrm{I}-1)$ & $\sigma_{d}^{2}+K \sigma_{e}^{2}+J K \sigma_{c s}^{2}$ \\
\hline 6 & $\mathrm{~S} \times \mathrm{P} / \mathrm{C}$ & $\mathrm{I}(\mathrm{Q}-1)(\mathrm{J}-1)$ & $\sigma_{d}^{2}+K \sigma_{e}^{2}$ \\
\hline 7 & $\mathrm{~S} \times \mathrm{A} / \mathrm{P} / \mathrm{C}$ & \multicolumn{2}{|c|}{$\mathrm{IJ}(\mathrm{Q}-1)(\mathrm{K}-1) \sigma_{\mathrm{d}}^{2}$} \\
\hline & $\begin{array}{l}\text { ocientes de quadras } \\
6: 7 . \text { Sendo que } \sigma \\
=\text { clones }, \mathrm{P}=\text { parcel }\end{array}$ & $\begin{array}{l}\text { médios para } \\
\text { referem-se a } \\
\mathrm{A}=\text { árvores, }\end{array}$ & $\begin{array}{l}\text { os testes } \mathrm{F}:(1+6):(2+5),(2+7):(3+6), 3: 7,4: 5, \\
\text { os efeitos aleatórios e fixo, respectivamente; } \\
\mathrm{S}=\text { seções. }\end{array}$ \\
\hline
\end{tabular}

Todos os componentes de variância foram calculados pelo método da máxima verossimilhança restrita (REML). As estimativas da herdabilidade no sentido amplo, ao nível de médias $\left(\mathrm{h}^{2}\right)$, foram determinadas de duas maneiras, considerando-se primeiramente a variação do caráter apenas entre árvores e posteriormente considerando-se também a variação do caráter em diferentes alturas, conforme mostram, respectivamente as fórmulas [3] e [4] abaixo:

$$
\begin{aligned}
& h^{2}{ }_{1}=\sigma^{2}{ }_{c} /\left(\sigma^{2}{ }_{c}+\sigma^{2} / J+\sigma^{2} / J K\right) \\
& h^{2}{ }_{2}=\sigma^{2}{ }_{c} /\left(\sigma_{c}^{2}+\sigma_{p}^{2} / J+\sigma^{2}{ }_{a} / J K+\sigma^{2}{ }_{c s} / Q+\sigma^{2}{ }_{d} J \mathrm{JQ}+\sigma^{2}{ }_{d} / J K Q\right)
\end{aligned}
$$

onde: $\quad \sigma^{2}$ é o componente da variância para clones;

$\sigma_{p}^{2}$ é o componente da variância para parcelas;

$\sigma^{2}{ }_{a}$ é o componente da variância para árvores;

$\sigma^{2}$ ss é o componente da variância para a interação seções x clone;

$\sigma^{2}$ é o componente da variância para o erro seções x parcelas;

$\sigma^{2}{ }_{d}$ é o componente da variância para o erro seções $x$ árvores; 
Os erros das estimativas de herdabilidade obtidas pela fórmula 3 foram calculados de acordo com o procedimento adotado por Vencovsky \& Barriga (1992).

Devido ao fato de os dados de RP, RT, BL, TB, F, V e CN não apresentarem originalmente distribuição normal e homogeneidade de variâncias, os mesmos foram transformados utilizando-se a transformação ótima de Box \& Cox (1964) para analisar a significância dos testes $F$, das correlações e das comparações de médias.

Para a comparação das médias de clones utilizou-se o método de comparação múltipla com o melhor (Hsu, 1997), visto que em se tratando de seleção a comparação de todos os tratamentos entre si não é interessante (Chew, 1977).

Todas as análises estatísticas foram realizadas através do software SAS (versões 6.08 e 6.11 ).

\subsection{Resultados e discussão}

Os valores médios, intervalos de variação dos clones, valores de $\mathrm{F}$, coeficientes de herdabilidade no sentido amplo e respectivos erros, considerando-se somente a medição na primeira tora, encontram-se na Tabela 3 . Os valores de herdabilidade encontrados para rachaduras (RP, RT, TB, BL) e empenamentos (F, V e E) indicam que estes caracteres são fortemente herdáveis em E. urophylla e portanto constituem-se em importantes indicadores sobre os quais devem basear-se os programas de seleção de árvores para serraria. 
Tabela 3: Média geral, intervalos de variação da média dos clones, valores de F para a diferença entre clones e estimativas da herdabilidade para todas as variáveis estudadas.

\begin{tabular}{c|ccc|cc}
\hline Código & Média & $\begin{array}{c}\text { Intervalo de } \\
\text { Variação }\end{array}$ & $\mathrm{F}$ & $\mathrm{H}_{1}{ }^{2}$ & Erro da Estimativa \\
\hline RP & 0,493 & $0,002-2,021$ & $5,46^{* * *}$ & 0,831 & 0,057 \\
RT & 0,792 & $0,146-3,474$ & $4,71^{* * *}$ & 0,822 & 0,060 \\
DS & 17,0 & $14,8-19,7$ & $2,12^{* *}$ & 0,534 & 0,156 \\
F & 2,19 & $1,23-3,52$ & $6,67^{* * *}$ & 0,829 & 0,057 \\
V & 3,80 & $2,09-6,09$ & $6,72^{* *}$ & 0,833 & 0,056 \\
HT & 25,5 & $19,3-30,6$ & $1,91^{*}$ & 0,479 & 0,175 \\
HF & 18,8 & $13,2-24,3$ & $1,72 \mathrm{~ns}$ & 0,409 & 0,198 \\
CP & 26,7 & $10,8-38,4$ & $2,34^{* *}$ & 0,568 & 0,145 \\
CN & 1,61 & $1,52-1,83$ & $1,09 \mathrm{~ns}$ & 0,066 & 0,313 \\
TB & 22,9 & $10,9-52,4$ & $4,34^{* * *}$ & 0,741 & 0,087 \\
E & 1,62 & $1,03-2,42$ & $2,85^{* * *}$ & 0,649 & 0,118 \\
BL & 27,7 & $6,6-76,1$ & $6,16^{* * *}$ & 0,810 & 0,064 \\
ST & 0,673 & $0,591-0,846$ & $2,61^{* *}$ & 0,616 & 0,129 \\
\hline
\end{tabular}

Obs.: ns $=$ não significativo; ${ }^{*},{ }^{*}, * * *$ singnificativo ao nível de $5 \%, 1 \%$ e $0,1 \%$, respectivamente. Os valores de DS, F, V, TB, E e BL estão em centímetros, enquanto HT e HF estão em metros.

O grau de competição entre as árvores pode ser inferido pelo valor do fator de estabilidade ST (DS/HT), cujo valor encontrado de 0,673 é inferior ao valor de 1,1 encontrado por Malan (1988) e de 1,1-1,4, calculado para os dados de Vignote et al. (1996). Calculando-se o fator de estabilidade a partir dos dados de DAP e alturas médias obtidos por Stape (1995) em uma população de Eucalyptus dunnii de 6 anos de idade verificou-se que este fator variou de 0,54 para $1,4 \mathrm{~m}^{2} /$ planta até 1,21 para $44 \mathrm{~m}^{2} /$ planta. A competição que pode começar antes do primeiro ano de idade, mesmo em 
espaçamento de $3 \times 3 \mathrm{~m}$, pode levar à subestimativas da variação genética (Bouvet, 1997). Este fato indica que se os resultados obtidos refletem as condições implícitas de alta competição entre árvores, então eles poderão ser majorados se comparados com rigor a povoamentos corretamente manejados para produção de madeira serrada.

O armazenamento de toras de forma submersa em água ou mesmo sob aspersão pode reduzir o grau da tensão de crescimento e de acordo com Haslett (1988b, 1990) este efeito pode ser considerável. Dessa forma algumas variáveis como as rachaduras de tábuas e os empenamento da madeira serrada podem ter sido subestimados pelo efeito do armazenamento sob aspersão a que ficaram submetidos as toras ainda com casca e depois os blocos. Entretanto, dadas as condições do presente ensaio, admite-se que esta interferência possa ser desprezada, tendo em vista que o seu enfoque principal baseia-se no entendimento das interações entre os caracteres e não apenas nas suas intensidades absolutas.

Quando foram consideradas as duas primeiras toras, obtiveram-se valores de herdabilidade no sentido amplo de 0,76 para $V, 0,50$ para RP e 0,46 para TB, menores do que os respectivos valores de $0,83,0,74$ e 0,60 , referentes aos mesmos clones e árvores, mas relativos somente à primeira tora. Verifica-se então uma considerável diminuição da herdabilidade quando considera-se também a variação dentro da árvore do que somente a primeira tora, visto que o ideal é que a seleção seja baseada incluindo as toras até uma altura comercial de serraria da árvore.

Os componentes de variância nulos da Tabela 4, obtidos pela aplicação do método REML, tinham sido negativos quando aplicado o método dos momentos. Confirma-se então a característica dos métodos de máxima verossimilhança de obtenção de estimativas não negativas, inclusive para dados não balanceados (Searle, 1971), ao contrário do método dos momentos, que podem resultar em negativos. Em todos os 3 caracteres analisados a contribuição relativa das árvores representou pouco (máximo 6 \%) em relação a variância total, ao contrário do erro S x A (20 a 37\%). 
Tabela 4: Componentes da variância estimados pelo metodo REML.

\begin{tabular}{ccccccc}
\hline Componente & RP & $\%$ & TB & $\%$ & $\mathrm{~V}$ & $\%$ \\
\hline$\sigma^{2}{ }_{c}$ & 0,1911 & 21,05 & 69,34 & 22,19 & 0,5901 & 39,06 \\
$\sigma_{\mathrm{p}}^{2}$ & 0,3887 & 42,81 & 160,68 & 51,43 & 0 & 0,00 \\
$\sigma_{\mathrm{a}}^{2}$ & 0,0049 & 0,54 & 0 & 0 & 0,0947 & 6,27 \\
$\sigma_{\mathrm{cs}}^{2}$ & 0,1084 & 11,94 & 15,84 & 5,07 & 0,2213 & 14,65 \\
$\sigma_{\mathrm{e}}^{2}$ & 0 & 0,00 & 4,29 & 1,03 & 0,0473 & 3,13 \\
$\sigma_{\mathrm{d}}^{2}$ & 0,2149 & 23,67 & 62,31 & 19,94 & 0,5574 & 36,89 \\
\hline
\end{tabular}

Tabela 5: Análise de variância para os caracteres RP e V, considerando a variação entre e dentro de árvores.

\begin{tabular}{lcccccc}
\hline Fonte de & \multicolumn{2}{c}{ Rach. RP } & \multicolumn{2}{c}{ Rach. TB } & \multicolumn{2}{c}{ Flecha do Vigote (V) } \\
\cline { 2 - 7 } Variação & GL & P $>$ F & GL & P $>$ F & GL & P>F \\
\hline $\mathrm{C}$ & 5 & 0,0676 & 11 & 0,0009 & 9 & 0,0013 \\
$\mathrm{P} / \mathrm{C}$ & 11 & 0,0000 & 18 & 0,0002 & 18 & 0,5691 \\
$\mathrm{~A} / \mathrm{P} / \mathrm{C}$ & 17 & 0,5429 & 30 & 0,6864 & 28 & 0,0649 \\
$\mathrm{~S}$ & 2 & 0,3871 & 1 & 0,0088 & 1 & 0,4331 \\
$\mathrm{~S} \times \mathrm{C}$ & 10 & 0,0027 & 11 & 0,2919 & 9 & 0,0152 \\
$\mathrm{~S} \times \mathrm{P} / \mathrm{C}$ & 22 & 0,4740 & 18 & 0,3503 & 18 & 0,3356 \\
$\mathrm{~S} \times \mathrm{A} / \mathrm{P} / \mathrm{C}$ & 34 & & 30 & & 28 & \\
\hline Obs.: C $=$ clones, $\mathrm{P}=$ parcelas, A = árvores, $\mathrm{S}=$ seções de altura \\
\hline
\end{tabular}


Tabela 6: Médias de flecha do vigote da costaneira (V) por clone em dois níveis de altura. Os respectivos coeficientes de variação encontram-se entre parênteses.

\begin{tabular}{|c|c|c|c|c|c|c|c|}
\hline \multirow{2}{*}{$\begin{array}{c}\text { Clone } \\
\mathrm{N}^{\circ}\end{array}$} & \multicolumn{2}{|c|}{ Altura Média } & \multirow{2}{*}{$\begin{array}{l}\text { Média } \\
(\mathrm{cm})\end{array}$} & \multirow{2}{*}{$\begin{array}{l}\text { Coefic. de } \\
\text { Variação } \\
(\%)\end{array}$} & \multirow{2}{*}{$\begin{array}{c}\mathrm{N}^{\mathrm{o}} \mathrm{de} \\
\text { Árvores }\end{array}$} & \multicolumn{2}{|c|}{ Altura das Árvores (m) } \\
\hline & $3,1 \mathrm{~m}$ & $6,5 \mathrm{~m}$ & & & & Média & Intervalo \\
\hline 6 & $\begin{array}{c}4,83 \\
(24,3)\end{array}$ & $\begin{array}{l}4,17 \\
(7,9)\end{array}$ & 4,50 & 19,8 & $\overline{6}$ & 25,43 & $22,4-30,0$ \\
\hline 7 & $\begin{array}{c}4,83 \\
(21,9)\end{array}$ & $\begin{array}{c}5,81 \\
(9,7)\end{array}$ & 5,32 & 17,9 & 6 & 26,20 & $22,0-30,0$ \\
\hline 12 & $\begin{array}{r}4,68 \\
(9,2)\end{array}$ & $\begin{array}{r}4,02 \\
(21,2)\end{array}$ & 4,35 & 16,8 & 6 & 29,50 & $28,0-30,0$ \\
\hline 18 & $\begin{array}{l}6,09 \\
(8,3)\end{array}$ & $\begin{array}{c}4,89 \\
(10,8)\end{array}$ & 5,49 & 14,5 & 6 & 30,47 & $29,8-31,0$ \\
\hline 19 & $\begin{array}{r}4,40 \\
(13,6)\end{array}$ & $\begin{array}{c}5,58 \\
(14,8)\end{array}$ & 4,99 & 18,5 & 6 & 22,27 & $18,7-28,5$ \\
\hline 20 & $\begin{array}{c}3,31 \\
(12,9)\end{array}$ & $\begin{array}{c}4,25 \\
(27,3)\end{array}$ & 3,78 & 25.6 & 6 & 27,18 & $26,3-28,0$ \\
\hline 21 & $\begin{array}{c}2,69 \\
(20,7)\end{array}$ & $\begin{array}{c}2,79 \\
(14,7)\end{array}$ & 2,7 & 17,1 & 6 & 22.90 & $19,5-28,5$ \\
\hline 27 & $\begin{array}{c}3,13 \\
(21,1)\end{array}$ & $\begin{array}{l}3,73 \\
(8,8)\end{array}$ & 3,4 & 16,8 & 4 & 19,28 & $19,4-19,7$ \\
\hline 38 & $\begin{array}{r}3,86 \\
(22,7)\end{array}$ & $\begin{array}{l}3,82 \\
(7,8)\end{array}$ & 3,8 & 15,8 & 4 & 24,28 & $20,2-28,2$ \\
\hline 39 & $\begin{array}{c}5,00 \\
(38,9)\end{array}$ & $\begin{array}{c}4,75 \\
(16,9)\end{array}$ & 4,9 & 29,3 & 6 & 24,9 & $21,4-29,0$ \\
\hline Média & 4,34 & 4,42 & & & & & \\
\hline
\end{tabular}


A Tabela 5 mostra, para o caracter $\mathrm{V}$, variações significativas para clones (C), não significativas entre as seções de altura (S) e significativas para $\mathrm{S} x \mathrm{C}$.

A Tabela 6 mostra as médias de encurvamento $\mathrm{V}$ de cada clone nas alturas 3,1 e $6,5 \mathrm{~m}$ sobre os quais é possível verificar que realmente não existe um padrão geral de variação destes caracteres para todos os clones. Além disto o comportamento de $\mathrm{V}$ foi indistinto na altura quando analisam-se as árvores dentro de cada clone. Isto pode ter sido conseqüência da existência das grandes variações periféricas nas tensões de crescimento (Saurat \& Gueneau ${ }^{13}$, 1976 citado por Kubler, 1987; Nicholson, 1973 e Nicholson et al., 1975), de variações no ângulo da grã da madeira (Archer ${ }^{14}$, 1979 citado por Archer, 1987) ou mesmo da tortuosidade da tora (Dinwoodie, 1966), especialmente quando a curvatura ocorre em dois planos perpendiculares.

A significativa interação $\mathrm{S} \times \mathrm{C}$ para as rachaduras $\mathrm{RP}$ é analisada nas alturas de $1,3,4,7$ e $8,1 \mathrm{~m}$ de cada clone na Tabela 7 . Observam-se clones em que há um aumento de intensidade de RP até $4,7 \mathrm{~m}$, seguido de uma diminuição até os $8,1 \mathrm{~m}$. Em outros, há uma diminuição contínua destas rachaduras com a altura, mas no geral não apresentam diferenças significativas entre as diversas posições verticais na árvore. Admite-se do ponto de vista industrial, que estas variações são muito pequenas comparadas com as próprias intensidades das rachaduras as quais constituem, de fato, num importante problema a ser resolvido no mais curto espaço de tempo possível. Os altos valores dos coeficientes de variação encontrados são conseqüentes da grande variabilidade verificada ao nível de árvores, e são muito provavelmente, reflexos da presença de nós na madeira, desvio da grã e variação da resistência mecânica da madeira à tração normal às fibras.

\footnotetext{
${ }^{13}$ SAURAT, J.; GUENEAU, P. Growth stresses in beech. Wood Science and Technology, V.10, n.2, p.111-123, 1976.

${ }^{14}$ ARCHER, R.R. On the distribution of the growth stresses. Part III:

The case of inclined grain. Wood science and Technology, v.13, p.67-78, 1979 .
} 
Observa-se também na Tabela 5 que a seção de altura (S) não tem um efeito significativo sobre as rachaduras de toras RP, mas significativo em TB. As rachaduras de extremidade das tábuas obtidas da primeira tora foram de $27 \mathrm{~cm}$ em média, maiores que as da segunda tora, onde este valor foi de $23 \mathrm{~cm}$ em média. Depreende-se portanto um significativo efeito do diâmetro para tensões periféricas supostas constantes ao longo do fuste da árvore. As exceções a esta regra podem ter ocorrido devido a presença de madeira de reação, nós, ou problemas no processamento dos blocos na serra francesa, como por exemplo os impactos na entrada da mesma.

Tabela 7: Médias das rachaduras de topo de toras com saco plástico (RP) por clone em dois níveis de altura. Os respectivos coeficientes de variação encontram-se entre parênteses.

\begin{tabular}{ccccccccc}
\hline Clone & \multicolumn{3}{c}{ Altura de Corte (m) } & Média & \multicolumn{2}{c}{$\mathrm{N}^{0}$ de } & \multicolumn{2}{c}{ Altura das Árvores (m) } \\
\cline { 2 - 4 } $\mathrm{N}^{0}$ & $1,3 \mathrm{~m}$ & $4,7 \mathrm{~m}$ & $8,1 \mathrm{~m}$ & & Cortes & Média & Amplitude \\
\hline 6 & 0,41 & 0,59 & 0,35 & 0,45 & 18 & 25,43 & $22,4-30,0$ \\
& $(109,0)$ & $(87,0)$ & $(107,4)$ & $(96,8)$ & & & \\
7 & 1,35 & 2,37 & 2,00 & 1,91 & 18 & 26,2 & $22,0-30,0$ \\
& $(77,2)$ & $(59,6)$ & $(66,8)$ & $(66,7)$ & & & \\
12 & 1,12 & 0,57 & 0,48 & 0,72 & 18 & 29,5 & $28,0-30,0$ \\
& $(36,2)$ & $(48,2)$ & $(39,4)$ & $(56,5)$ & & & \\
18 & 1,73 & 1,49 & 0,54 & 1,25 & 18 & 30,47 & $29,8-31,0$ \\
& $(27,8)$ & $(84,2)$ & $(19,7)$ & $(71,9)$ & & & \\
19 & 0,27 & 0,78 & 0,56 & 0,54 & 18 & 22,27 & $18,7-28,5$ \\
& $(133,0)$ & $(107,5)$ & $(115,0)$ & $(119,6)$ & & & \\
20 & 0,24 & 0,26 & 0,26 & 0,25 & 12 & 27,18 & $26,3-28,0$ \\
& $(36,8)$ & $(20,7)$ & $(34,9)$ & $(28,8)$ & & & \\
\hline Média & 0,89 & 1,06 & 0,72 & & & & \\
\hline
\end{tabular}


$\mathrm{Na}$ Tabela 8 encontram-se as correlações genéticas e fenotípicas, ao nível de totais de parcelas, considerando-se somente a medição na primeira tora da árvore. Em alguns casos encontraram-se valores elevados de correlação que não foram significativos. Isto ocorreu porque a magnitude dos valores foi calculada com os dados originais e a significância foi verificada com os dados, transformados quando necessário, sob distribuição normal.

Analisando-se as correlações fenotípicas de HT com ST e com as rachaduras RP e RT evidenciadas na Tabela 8, verifica-se que as árvores mais altas geralmente são as mais esbeltas e as que racham com maior intensidade. Este efeito pode ser explicado pela competição por luz nas árvores, pois ST e CP estão positiva e significativamente correlacionados fenotipicamente. $\mathrm{O}$ mesmo efeito de competição nas rachaduras também foi constatado por Ferrand $(1982,1983)$. A literatura também cita que povoamentos de eucalipto após desbastes pesados tem menores tensões de crescimento do que aqueles sujeitos a leves e moderados desbastes. $\mathrm{O}$ diâmetro das árvores é o que realmente influi no gradiente de tensões (Haslett, 1988 e Hillis, 1984), e o a influência da idade (Hillis, 1984 e Vignote et al., 1996) perde a sua importância.

As correlações fenotípicas significativas das rachaduras de extremidades de toras RP e RT com o diâmetro $(0,51$ e 0,48$)$ e com a altura total $(0,75$ e 0,65 ) foram mascaradas pelas ambientais, especialmente devido a este efeito de competição entre as árvores, por isto não concordam com a literatura. Os poucos trabalhos existentes mencionam coeficientes de correlação fenotípica entre as rachaduras de topo de toras e diâmetros variando de 0,22 (Malan, 1988) a ausentes (Malan, 1992) e coeficientes de correlação fenotípica entre diâmetro e tensões de crescimento variando de $-0,0263$ e $-0,0459$ (Vignote et al,, 1996). Encontraram-se na literatura também coeficientes de correlação fenotípica entre rachaduras de topo de toras com altura, da ordem de 0,26 (Malan, 1988) e entre tensões de crescimento e altura da ordem de 0,0259 (Vignote et al., 1996). 


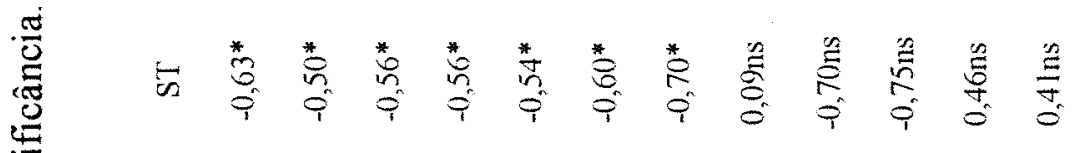

兽

$\sum_{\substack{0 \\ 0}}$

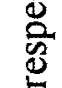

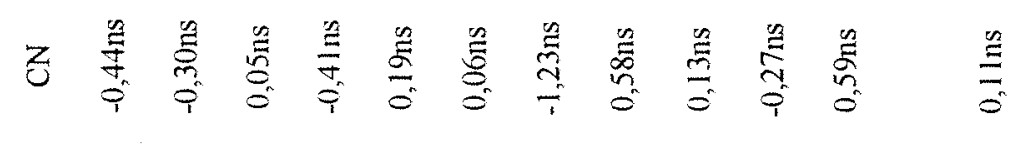

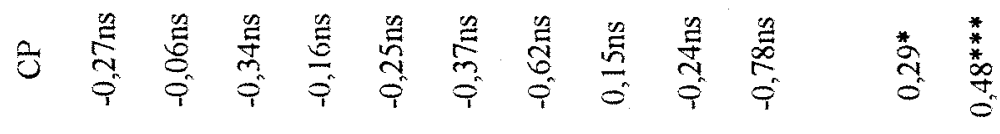

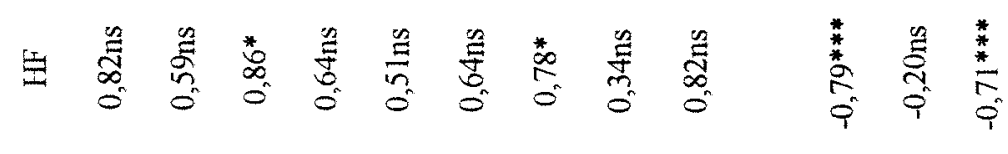

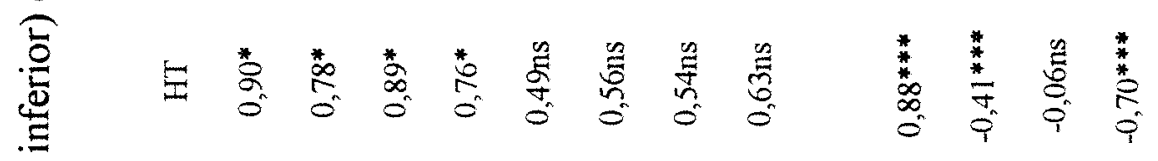

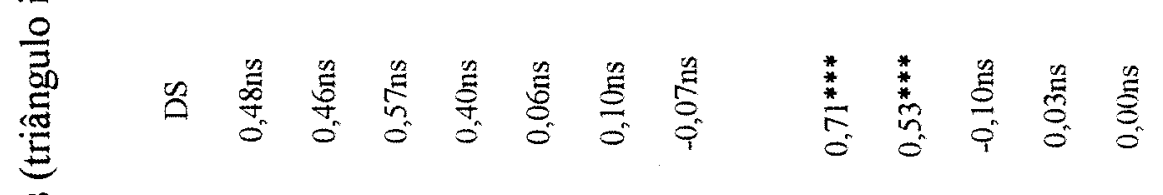

$\frac{\mathscr{Z}}{\tilde{C}}$

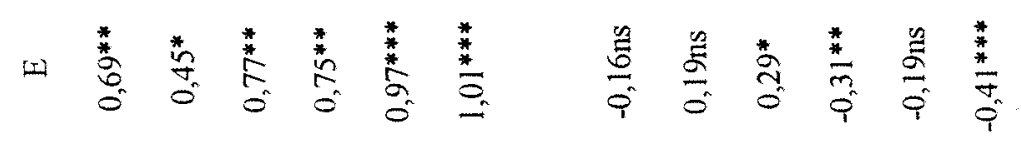

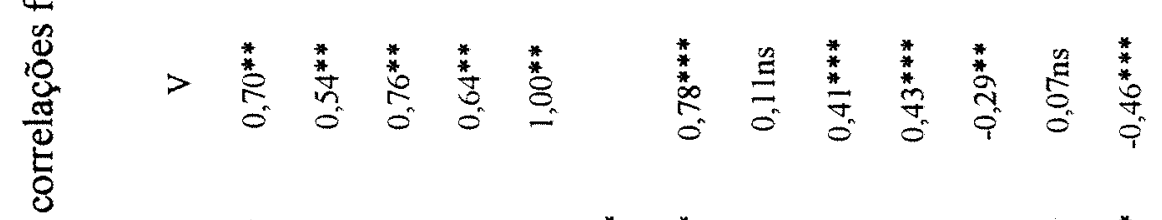

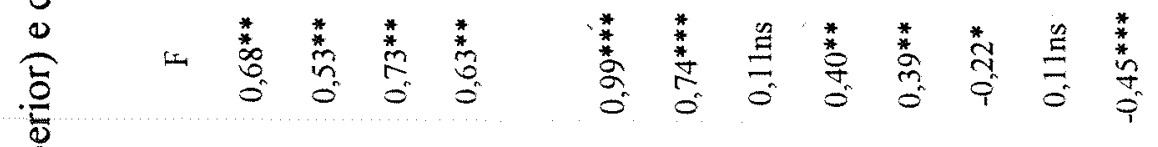

$\frac{5}{3}$

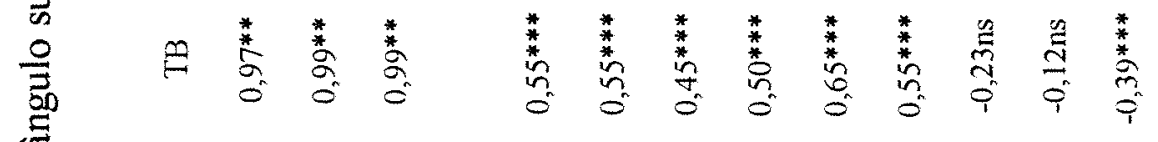

胥

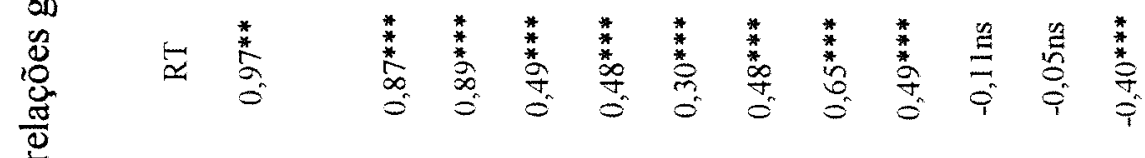

苛

$\frac{\infty}{\frac{\pi}{0}}$

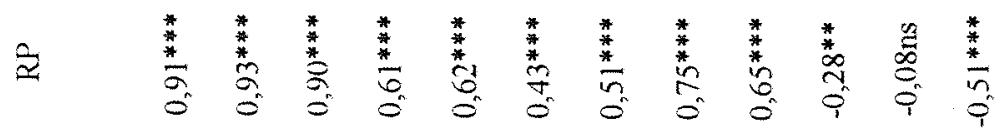

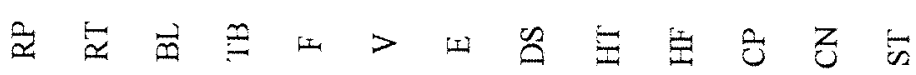


A porcentagem de rachaduras de topo de toras protegidas com saco plástico (RP) ou mesmo livre (RT) foi um eficiente indicador para a seleção de árvores com baixa intensidade de rachaduras na madeira serrada (TB), pois encontraram-se correlações fenotípicas de 0,90 e 0,89 , respectivamente. Deve-se ter o cuidado de que as condições de medição no campo estejam padronizadas, porque podem ocorrer grandes variações oriundas das tensões de secagem. A flecha da costaneira (F) ou a flecha do vigote obtido desta $(\mathrm{V})$, obtida em condições padronizadas, também foi um considerados eficiente indicador para seleção de árvores produtoras de madeira serrada com baixos níveis de encurvamento.

Obtiveram-se muito poucas diferenças entre as correlações fenotípicas das rachaduras de tábuas verdes (TB) com as rachaduras de toras $\operatorname{RP}(0,90)$ e RT $(0,89)$. A diferença de magnitude entre as rachaduras de topo RP e RT medidas em faces adjacentes como mostra a Tabela 2 deve-se à interação de rachaduras de tensões de crescimento com rachaduras oriundas do processo de secagem, pois as rachaduras de topo de toras adjacentes são altamente correlacionadas (Purnell, 1988 e Schacht \& Garcia, 1997). Ao considerar-se que rachaduras devido ao colapso podem começar em 20 minutos após o secionamento do fuste (Barnacle, 1971) e que rachaduras devido à secagem abaixo do ponto de saturação das fibras começam geralmente após o $4^{\circ}$ dia (Bariska, 1990), então deduz-se que o colapso pode ser responsável pela liberação de grande parte das tensões de crescimento no topo das toras, o qual não necessariamente influencia no TB.

As altas correlações genéticas das rachaduras de toras RP e RT com as rachaduras $\mathrm{TB}(0,97$ e 0,99 respectivamente) mostram a eficiência da seleção ainda no campo quando visa-se melhorar o rendimento em madeira serrada verde. As significativas correlações genéticas das rachaduras de toras RP e RT com E $(0,69$ e 0,45 respectivamente) indicam que a seleção também no campo e baseada unicamente nas rachaduras de extremidades das toras pode reduzir consideravelmente o encurvamento das tábuas. Esta seleção indireta reflete-se diretamente sobre a qualidade de peças serradas longas. 


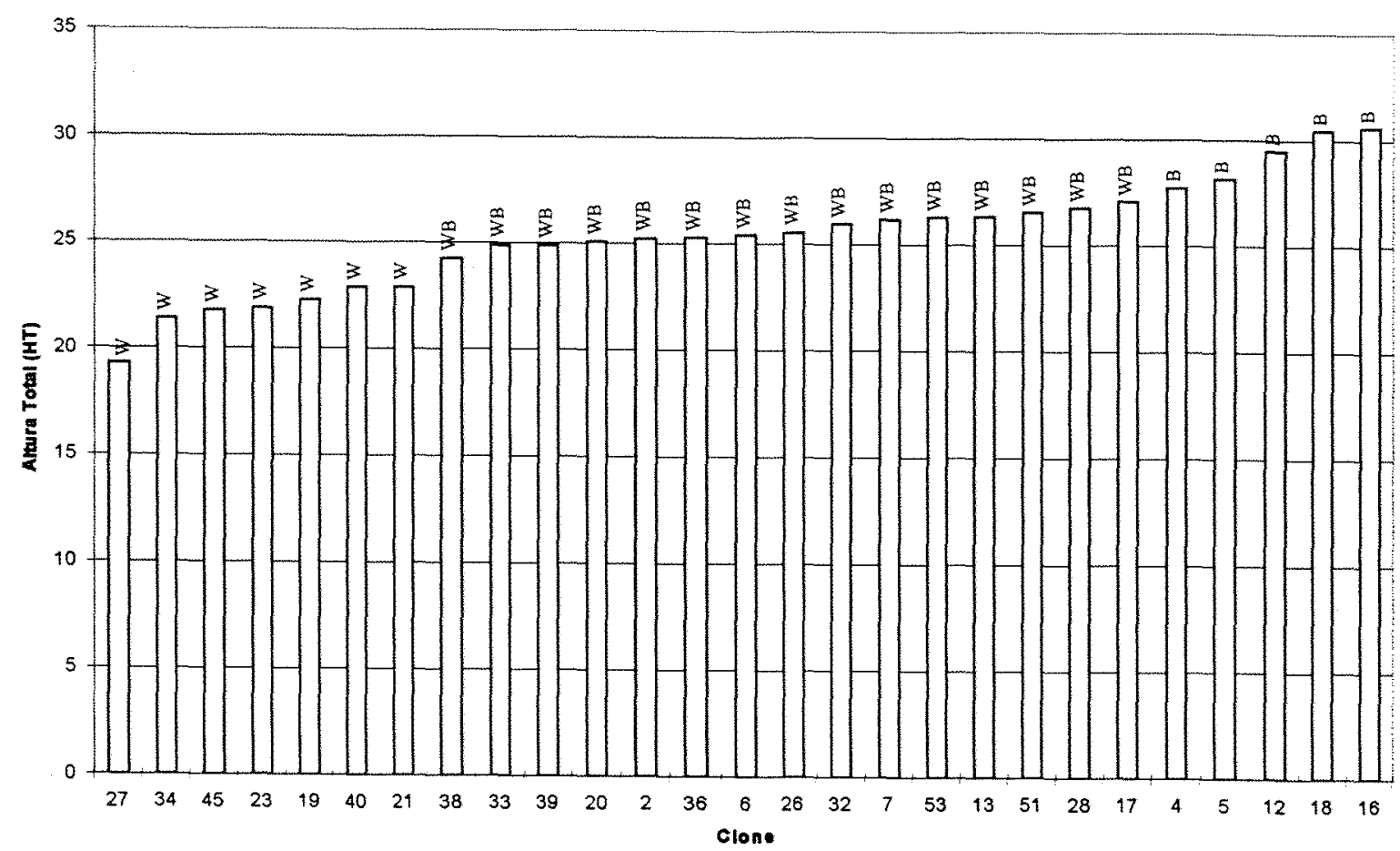

(a)

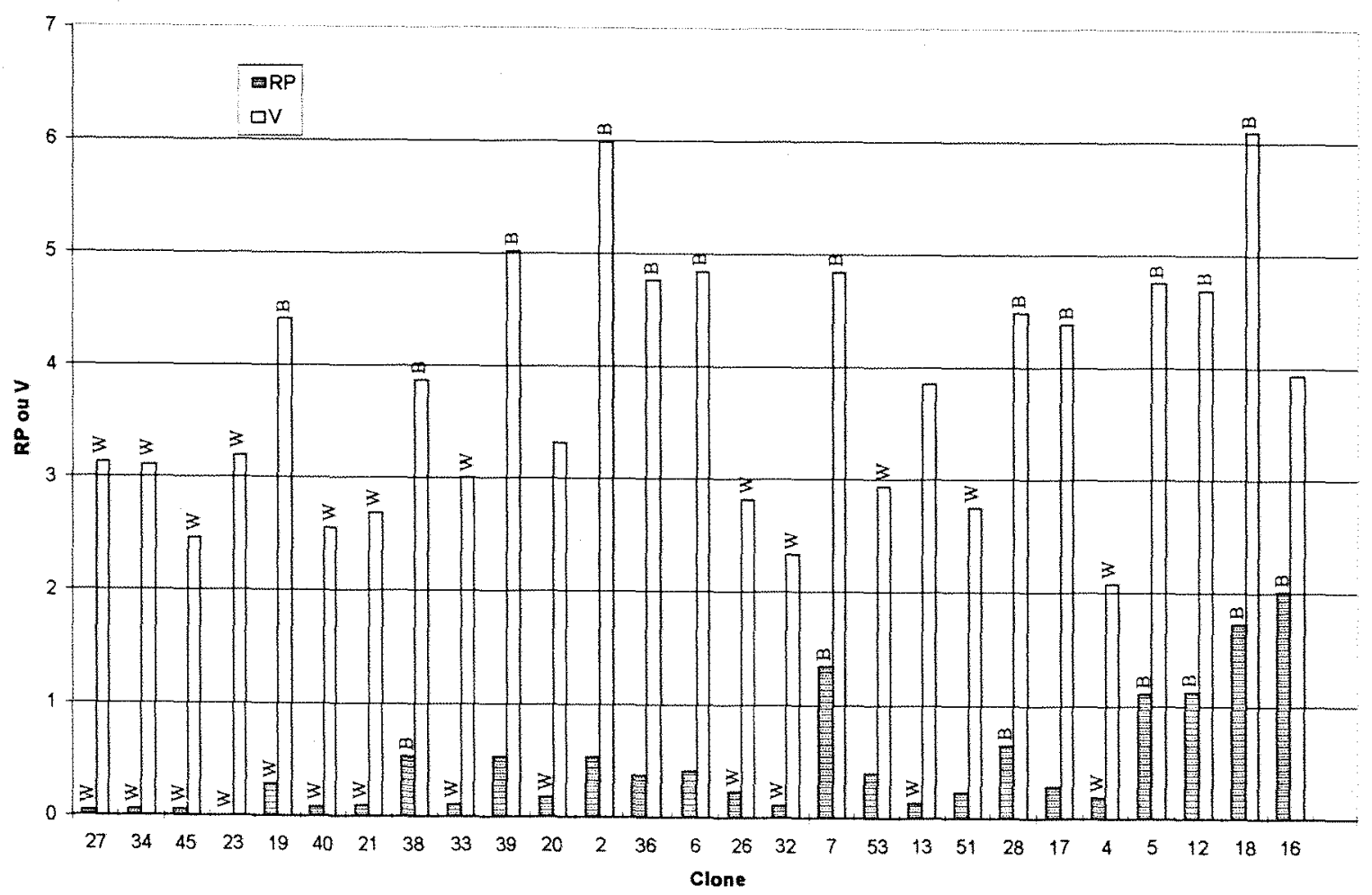

(b) 


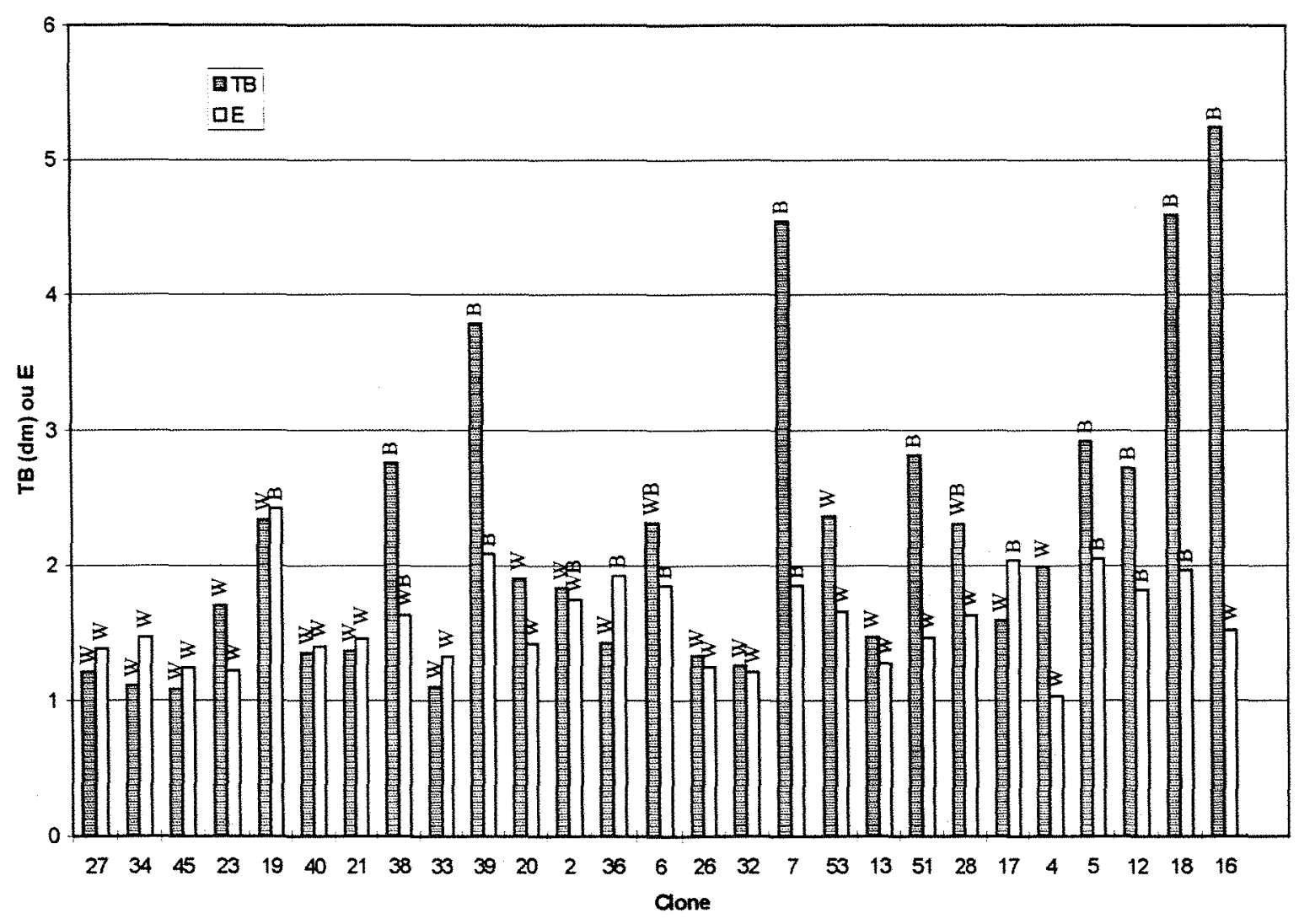

(c)

Figura 6: Comparação de médias dos caracteres HT - altura total da árvore (a); RP rachadura de topo de toras com saco plástico e V - flecha do vigote (b); TB rachadura de tábuas e $\mathrm{E}$ - encurvamento de tábuas (c); onde $\mathrm{B}$ representa $\mathrm{O}$ provável maior valor e $\mathrm{W}$ representa o provável menor valor a um nível de 5 $\%$ de probabilidade.

A variável DS não correlaciona-se geneticamente com rachaduras ou empenamentos, fato este que possibilita o melhoramento para baixos niveis de tensões de crescimento sem perder produtividade, com a vantagem de ser não destrutivo. 
As correlações genéticas negativas de ST com as rachaduras e empenamentos indicam que a seleção indireta de clones com alto quociente DAP/HT podem ser um meio de reduzir o nível de tensões de crescimento na população melhorada.

A Figura 6 apresenta as comparações de médias dos caracteres HT, RP, $\mathrm{V}, \mathrm{TB}$ e E, agrupando os clones nos de prováveis maiores (B) e menores (W) valores, ao nivel de $95 \%$ de probabilidade. Ao realizar-se a seleção genética simultânea para maior HT, menor RP e menor V, verifica-se nas Figuras $6(\mathrm{a})$ e $6(\mathrm{~b})$ que os melhores clones seriam os indicados pelos números 4, 26, 32 e 33 e na Figura 6(c) observa-se que estes mesmos clones seriam selecionados na serraria, pelas menores prováveis médias de TB e E. Esta coincidência confirma a possibilidade de seleção indireta, graças às correlações genéticas existentes entre estes caracteres. A seleção genética simultânea no sentido inverso, levaria da mesma forma, à identificação dos piores clones identificados pelos números 7,28 e 38 .

Observa-se também que, em geral, os clones que apresentam os menores valores de RP são os que apresentam no desdobro os menores valores de $\mathrm{V}$, excetuando-se o clone 19. A associação de TB e E, para a qual obteve-se um coeficiente de correlação genética de 0,75 , visto na Tabela 8 , é muito interessante porque indica a possibilidade real de obterem-se peças mais longas e ao mesmo tempo menos empenadas, culminando portanto num maior rendimento de peças de melhor qualidade. Entretanto o número de exceções aumenta consideravelmente em virtude da provável influência de grã entrecruzada, visto que a mesma dificulta de forma decisiva na manifestação das rachaduras na madeira e de forma pouco importante no empenamento.

\subsection{Conclusões}

As rachaduras e empenamentos da madeira serrada verde são caracteres altamente herdáveis e podem ser selecionados geneticamente no campo pelas rachaduras 
de toras, ou na serraria pela flecha da costaneira ou do vigote desta, sem afetar o melhoramento genético para o diâmetro.

Grande parte das rachaduras de toras com o topo livre (RT) é resultante da interação de tensões de crescimento com tensões de secagem e portanto dependem muito do déficit de saturação de umidade no ar, o que pode resultar em erros na seleção dos clones. Dessa forma é muito importante padronizarem-se as condições ambientais de medição durante os trabalhos de seleção. A presença de nós, que interfere tanto nas rachaduras RP quanto na RT, pode também introduzir erros, influenciando na seleção baseada em características de rachaduras.

As correlações fenotípicas entre as rachaduras de extremidades de tora e o DAP da árvore, que foram altamente significativas, refletem uma influência ambiental muito forte, dentro da qual pode-se citar a competição entre as árvores como uma das mais importantes.

A seleção genética indireta de clones pouco esbeltos, ou com alto quociente DAP/HT, pode ser um meio de reduzir o nível das tensões de crescimento sem destruir a árvore.

A posição ao longo do fuste da árvore não influenciou a intensidade de rachaduras de toras e o encurvamento da flecha do vigote da costaneira, mas teve influência significativa sobre a intensidade das rachaduras de tábuas.

\subsection{Agradecimentos}

Os autores agradecem a Champion Papel e Celulose Ltda por todo apoio recebido na coleta de dados e material em campo. Também agradecem à Serraria da ESALQ e do Instituto de Pesquisas Tecnológicas de São Paulo pelo apoio no processamento das toras. 


\section{CONCLUSÕES GERAIS}

É possível isolar-se as rachaduras de extremidades das toras que resultam exclusivamente das tensões de crescimento das tensões advindas da secagem, pela simples proteção dessas extremidades com saco plástico previamente umidecido internamente.

A intensidade da rachadura da extremidade de uma tora é altamente correlacionada com a intensidade da rachadura da seção transversal adjacente da tora seguinte. Isto permitiu inferir que grande parte das rachaduras causadas por tensões de crescimento são liberadas devido ao processo de secagem, podendo estas serem de duas a tres vezes maiores que nas toras com a extremidade protegida.

As rachaduras de extremidade de toras, de blocos e das peças serradas, bem como os empenamentos da costaneira e das peças serradas são indicadores que explicam eficazmente as consequências da tensão de crescimento que existia na árvore, e são altamente herdáveis. Portanto podem ser utilizados nos programas de melhoramento florestal como caracteres indicativos de produtividade e de qualidade da madeira serrada.

O melhoramento de qualquer tipo de rachadura indiretamente favorecerá o melhoramento de todos os tipos de empenamentos da madeira serrada, pois todos estes caracteres estão positiva e significativamente correlacionados geneticamente.

A correlação genética entre qualquer parâmetro de qualidade da madeira ligado à tensão de crescimento e o DAP da árvore é nula, fato este que possibilita o melhoramento genético dos citados caracteres de forma independente do melhoramento genético voltado para o crescimento em diâmetro. 
A porcentagem das rachaduras de topo das toras, em padronizadas condições de medição (principalmente secagem), a flecha da costaneira ou do vigote desta são caracteres indicados para seleção de árvores superiores, devendo ser incluídos em programas de melhoramento genético que visem qualidade de madeira serrada.

A significativa correlação negativa das rachaduras e empenamentos com a relação entre DAP e altura total da árvore, chamada fator de estabilidade, possibilita o melhoramento destes caracteres através da seleção indireta.

O aumento da altura ao longo do fuste da árvore não tem influência nas rachaduras de toras e na flecha do vigote da costaneira, mas a intensidade de rachaduras de tábuas diminui significativamente com o aumento da altura. 


\section{REFERÊNCIAS BIBLIOGRÁFICAS}

ARCHER, R.R. Growth stresses and strains in trees. Berlin: Springer Verlag, 1987. $240 \mathrm{p}$.

BARBIN, D. Componentes de variância. Piracicaba: ESALQ, 1993. 108p.

BARISKA, M. A method for predicting timber quality in eucalypts. In: MANAGEMENT OF EUCALYPTUS GRANDIS IN SOUTH AFRICA, Stellenbosch, 1990. Proceedings. Stellenbosch: Southern African Institute of Forestry, 1990. p.215-228.

BOUVET, J.M. Effect of spacing on juvenile growth and variability of Eucalyptus clones. Canadian Journal of Forest Research, v.27, p.174-179, 1997.

BOYD, J.D. Tree growth stresses II - the development of shakes and other visual failures in timber. Australian Journal of Applied Science, v.1, p.296-312, 1950.

BOYD, J.D. Tree growth stresses - Part V: evidence of an origin in differentiation and lignification. Wood Science and Technology, v.6, p.251-262, 1972.

BOYD, J.D. Relationships between fibre morphology, growth strains and physical properties of wood. Australian Forest Research, v.10, n.4, p.337-360, 1980.

BURDON, R.D.; SHELBOURNE, C.J.A. The use of vegetative propagation for genetic and physiological information. New Zealand Journal of Forestry Science, v.4, n.2, p.418-425, 1974.

CHAFE, S.C. Growth stress in trees. Australian Forest Research, v.9, n.3, p.203-223, 1979. 
CHAFE, S.C. Variations in longitudinal growth stress, basic density and modulus of elasticity with height in the tree. Australian Forest Research, v.11, n.1, p.79-82, 1981.

CHAFE, S.C. Variation in longitudinal growth stress with height in trees of Eucalyptus nitens Maiden. Australian Forest Research, v.15, n. 1, p.51-55, 1985.

CHEW, V. Comparisons among treatment means in an analysis of variance. Washington: USDA, 1977. 64p.

CONRADIE, W.E. Utilization of South African grown Eucalyptus grandis (W.Hill ex Maiden) as veneer logs. Part 1 . Control of end-splitting in veneer logs. CSIR, 1980. (Special Report, 206).

DINWOODIE, J.M. Growth stresses in timber - a review of literature. Forestry, v.39, n.2 p.162-170, 1966.

DODD, R.S.; POWER, A.B. Clarification of the term topophysis. Silvae Genetica, v.37, n. 1, p. 14-15, 1988.

EDWARDS, D. W. Defects of fast-grown eucalypts in New South Wales Australia. In: IUFRO MEETING DIVISION, 5., Pretoria, 1973. Proceedings. Pretoria: IUFRO, 1973. v.2, p.256-270.

ELDRIDGE, K.; DAVIDSON, J.; HARWOOD, C.; VAN WYK, G. Eucalypt domestication and breeding. Oxford: Clarendon Press, 1994. 288p.

FALCONER, D.S.; MACKAY, T.F.C. An introduction to quantitative genetics. 4.ed. New York: Longman \& Wiley, 1996. 464p.

FERNANDES, P.S. Variações de densidade da madeira e suas relações com as tensões de crescimento em progênies de Eucalyptus urophylla S.T. Blake. Piracicaba, 1982. 85p. Dissertação (Mestrado) - Escola Superior de Agricultura "Luiz de Queiroz", Universidade de São Paulo.

FERRAND, J.C. Etude des contraintes de croissance III - Eucalyptus delegatensis et Eucalyptus nitens: influence de la sylviculture et de la station. Annales de Sciences Forestieres, v.39, n.4, p.355-378, 1982. 
FERRAND, J.C. Growth stresses and silviculture of eucalypts. Australian Forest Research, v.13, n.1, p.75-81, 1983.

GARCIA, J.N. Estado de tensão em árvores e de deformação em peças de madeira serrada. São Paulo, 1992. 243p. Tese (Doutorado) - Escola Politécnica, Universidade de São Paulo.

GARCIA, J.N. Técnicas de desdobro de eucalipto. In: SEMINÁRIO INTERNACIONAL DE UTILIZAÇÃO DA MADEIRA DE EUCALIPTO PARA SERRARIA, São Paulo, 1995. Anais. Piracicaba: IPEF/IPT, 1995. p.59-67.

GARCIA, J.N.; ROCHA, J.S. Variability of amazonian species and its influence on wooden structure safety. In: EUROPEAN WORKSHOP ON APPLICATION OF STATISTICS AND PROBABILITIES IN WOOD MECHANICS, Bordeaux, 1996. Proceedings. Bordeaux: CNRS/INRA, 1996. /No prelo/.

HARRIS, J.M. Spiral grain and wave phenomena in wood formation. Berlin: Springer Verlag, 1989. 214p.

HASLETT, A. N. Properties and utilisation of exotic speciality timbers grown in New Zealand (part V: ash eucalypts and Eucalyptus nitens) FRI Bulletin, v.119, 19p. 1988.

HASLETT, A. N. Properties and utilisation of exotic speciality timbers grown in New Zealand (part VI: eastern blue gums and stringy barks) FRI Bulletin, v.119, 21p. 1990.

HILLIS, W.E. Wood quality and utilization. In: HILLIS, W.E.; BROWN, A.G. Eucalyptus for wood production. 2.ed. Adelaide: CSIRO, 1978. p.259-289.

HSU, J.C. Multiple comparisons: theory and methods. New York: Chapman \& Hall, 1997. $277 \mathrm{p}$.

JACOBS, M.R. The fibre tension of woody stems, with special reference to the genus Eucalyptus. Canberra: Commonwealth Forestry Bureau, 1938. 37p. (Bulletin, 22). 
JACOBS, M.R. The growth stresses of woody stems. Canberra: Commonwealth Forestry Bureau, 1945.67p. (Bulletin, 28).

JACOBS, M.R. Stresses and strains in tree trunks as they grow in lenght and width. Forestry and Timber Bureau, v.96, 15p, 1965.

JOUREZ, B. Le bois de tension 1. Définition et distribution dans l'arbre. Biotechnologie Agronomie Societé et Environnement, v.1, n.2, p.100-112, 1997.

KEMPTHORNE, O. An introduction to Genetic Statistics. New York: John Wiley \& Sons Inc., 1969. 545p.

KUBLER, H. Growth stresses in trees and related wood properties. Forest Products Abstracts, v.10, n.3, p.61-119, 1987.

LAUSBERG, M.J.F.; COWN, D.J.; GILCHRIST, K.F.; SKIPWITH, J.H.; TRELOAR, C.R. Physiological aging and site effects on wood properties of Pimus radiata. New Zealand Journal of Forestry Science, v.25, n.2, p, 189-99, 1995.

LIBBY, W.J.; JUND, E. Variance associated with cloning. Heredity, v.17, p.553-540, 1962.

MALAN, F.S. The control of end splitting in sawlogs: a short literature review. South African Forestry Journal, v.109, p.14-18, 1979.

MALAN, F.S. Studies on the phenotypic variation in growth stress intensity and its association with tree and wood properties of South African grown Eucalyptus grandis (Hill ex Maiden). Stellenbosch, 1984. 258p. Thesis (Ph.D.) - University of Stellenbosch.

MALAN, F.S. The reduction of high levels of growth stress in Eucalyptus grandis - Is tree breeding our only solution? Wood Southern Africa, v. 12, n. 10, p.19-20, 1987.

MALAN , F.S. Relationships between growth stress and some tree characteristics in South African grown Eucalyptus grandis. South African Forestry Journal, v.144, p.43-46, 1988.

MALAN, F.S. The wood properties and qualities of three south african-grown eucalypt hybrids. South African Forestry Journal, v. 167, p.35-44, 1993. 
MALAN, F.S. Eucalyptus improvement for lumber production. In: SEMINÁRIO INTERNACIONAL DE UTILIZAÇÃO DA MADEIRA DE EUCALIPTO PARA SERRARIA, São Paulo, 1995. Anais. Piracicaba: IPEF/IPT, 1995. p.1-19.

MALAN, F.S.; HOON, M. Effect of initial spacing and thinning on some wood properties of Eucalyptus grandis. South African Forestry Journal, v.163 p.13-20, 1992.

MARDER, M. Cracks of doom. New Scientist, v.2097, p.32-35, 1997.

MARTIN, B.; COSSALTER, C. Les eucalyptus des iles de la sonde. Bois et Forêts des Tropiques, v.163, p.3-25.

MATTHECK, C.; KUBLER, H. Wood: the internal optimization of trees. Berlin: Springer Verlag, 1995. 129p.

MATTHECK, C.; WALTHER, F. Eine neue fälltechnik zur vermeidung von hirnrissen in laubbäumen. Allgemeine Forst und Jagdzeitung, v.162, p.181-185, 1991.

NICHOLLS, J.W.P.; PEDERICK, L.A.; BROWN, A.G. A summary of the ortet-ramet relationship in wood characteristics of Pinus radiata. Appita, v.30, n.6, p.496-502, 1997.

NICHOLSON, J.E. Growth stress differences in eucalypts. Forest Science, v.19, n.3, p.169-174, 1973.

NICHOLSON, J.E.; HILLIS, W.E.; DITCHBURNE, N. Some tree growth -wood property relationships of eucalypts. Canadian Journal of Forest Research, v.5, n.3, p.424-432, 1975.

OLESEN, P.O. On cyclophysis and topophysis. Silvae Genetica, v.27, n.5, p.173-178, 1978.

PAGE, M.W. Production of sawn wood from small eucalypt logs. In: HILLIS, W.E.; BROWN, A.G. Eucalyptus for wood production. Adelaide: CSIRO, 1978, p.322327. 
PONCE, R.H. Eucalipto como madeira serrada. SIMPÓSIO BRASILEIRO DE PESQUISA FlORESTAL, 1., Belo Horizonte, 1993. Anais. Belo Horizonte: SIF, 1993. p.79-86.

PRYOR, L.D.; WILLIAMS, E.R.; GUNN, B.V. A morphometric analysis of Eucalyptus urophylla and related taxa with descriptions of two new species. Australian Systematic Botany, v.8, p.57-70, 1995.

PURNELL, R.C. Variation in wood properties of Eucalyptus nitens in a provenance trial on the eastern transvaal highveld in South Africa. South African Forestry Journal, v. 144, p.10-22, 1988.

SCHACHT,L.; GARCIA, J.N. Variação entre e intra clones nas rachaduras de topo em Eucalyptus urophylla. S.T.Blake In: CONFERENCIA IUFRO SOBRE SILVICULTURA E MELHORAMENTO DE EUCALIPTOS, Salvador, 1997. Anais. Colombo: EMBRAPA/CNPF, 1997. p.401-404.

SEARLE, S.R. Linear models. John Wiley, New York, 1971. 532p.

SKOLMEN, R.G. Characteristics and amount of brittleheart in Hawaii-grown robusta eucalyptus. Wood Science, v.6, n. 1, p.22-29, 1973.

SKOLMEN, R.G. Lumber potential of 12-year-old saligna eucalyptus trees in Hawaii. Washington: USDA, Forest Service Research, 1974. 7 p. (Research Note, PSW-288).

STAPE, J.L. Utilização de delineamento sistemático tipo "leque" no estudo de espaçamentos florestais. Piracicaba, 1995. 86p. Dissertação (Mestrado) - Escola Superior de Agricultura "Luiz de Queiroz", Universidade de São Paulo.

SWEET, G.B.; HARRIS, J.M. Wood properties of Pinus radiata: seed grown trees compared with grafts from different-aged ortets. New Zealand Journal of Forest Science, v.6, n.1, p.114-121, 1976.

VENCOVSKY, R. Herança quantitativa. In: PATERNIANI, E. (Coord.) Melhoramento e produção de milho, Piracicaba: Fundação Cargill, 1987, v.1, p.137-214. 
VENCOVSKY, R.; BARRIGA, P. Genética biométrica no fitomelhoramento. Ribeirão Preto: Sociedade Brasileira de Genética, 1992. 486p.

VERCOE, T.K; HOUSE, A.PN. Genetic resources of Eucalyptus urophylla S T Blake. BREEDING TROPICAL TREES CONFERENCE, Cartagena; Cali, 1992. IUFRO, 1992. p.183-188.

VIGNOTE, S.; MOLINERO, I; GERARD, J.; DIETZ, M.R. Estudio de las tensiones de crecimiento del Eucalyptus globulus Labill en Galicia y su relacion con las caracteristicas de la estacion y morfologicas del propio arbol. Investigacion Agraria: Systemas y Recursos Forestales, v.5, n. 1 p. 153-176, 1996.

VILLIERS, A.M. Utilisation problems with some eucalypts in South Africa. IUFRO MEETING DIVISION 5, Pretoria, 1973. Proceedings. Pretoria: IUFRO, 1973. v.2, p.238-255.

WALKER, J.C.F. Characteristics of stemwood and their manipulation. In: WALKER, J.C.F., BUTTERFIELD, B.G., LANGRISH, T.A.G., HARRIS, J.M., UPRICHARD, J.M. Primary wood processing: principles and practice. London: Chapman \& Hall, 1993. p. 153-196.

WATT, M.P.; DUNCAN, E.A.; ING, M; BLAKEWAY, F.C.; HERMAN, B. Field performance of micropropagated and macropropagated Eucalyptus hybrids. South African Forestry Journal, v. 173, p. 17-21, 1995.

WILHELMY, V.; KUBLER, H. Stresses and checks in log ends from relieved growth stresses. Wood Science, v.6, n.2, p. 136-142, 1973.

WILKINS, A.P. Nature and origin of growth stresses in trees. Australian Forestry, v. 49, n. 1, p. $56-62,1986$.

WILKINS, A.P.; KITAHARA, R. Relationship between growth strain and rate of growth in 22 year-old Eucalypus grandis. Australian Forestry, v.54, n. 1/2, p.95-98, 1991a. 
WILKINS, A.P.; KITAHARA, R. Silvicultural treatments and associated growth rates, growth strains and wood properties in 12.5-year-old Eucalyptus grandis. Australian Forestry, v.54, n.1/2, p.99-104, 1991b.

WILSON, P.J. Splitting studies on logs of Eucalyptus macarthurii, E. elata, and E. radiata. In: INSTITUTE FOR COMMERCIAL FORESTRY RESEARCH. 1985 Annual Report - 1985. Pietermaritzburg, 1985. p.135-142.

YAO, J. Relationships between height and growth stresses within and among white ash, water oak, and shagbarl hickory. Wood Science, v. 11, n.4, p.246-251, 1979.

ZOBEL, B.; JETT, J.B. Genetics of wood production. Berlin: Springer Verlag, 1995. $337 \mathrm{p}$. 